\title{
Communication patterns following the acquisition of a sexually transmitted infection
}

\author{
Courtney Vail Fletcher \\ West Virginia University
}

Follow this and additional works at: https://researchrepository.wvu.edu/etd

\section{Recommended Citation}

Fletcher, Courtney Vail, "Communication patterns following the acquisition of a sexually transmitted infection" (2005). Graduate Theses, Dissertations, and Problem Reports. 841.

https://researchrepository.wvu.edu/etd/841

This Thesis is protected by copyright and/or related rights. It has been brought to you by the The Research Repository @ WVU with permission from the rights-holder(s). You are free to use this Thesis in any way that is permitted by the copyright and related rights legislation that applies to your use. For other uses you must obtain permission from the rights-holder(s) directly, unless additional rights are indicated by a Creative Commons license in the record and/ or on the work itself. This Thesis has been accepted for inclusion in WVU Graduate Theses, Dissertations, and Problem Reports collection by an authorized administrator of The Research Repository @ WVU. For more information, please contact researchrepository@mail.wvu.edu. 
Communication Patterns Following the Acquisition of a Sexually Transmitted Infection

\author{
Courtney Vail Fletcher
}

\author{
Thesis submitted to the \\ Eberly College of Arts and Sciences \\ at West Virginia University \\ in partial fulfillment of the requirements \\ for the degree of \\ Master of Arts \\ in \\ Communication Theory and Research
}
Melanie Booth-Butterfield, Ph.D., Chair
Maria Brann, Ph.D.
Rebecca M. Chory-Assad, Ph.D.

Department of Communication Studies

\author{
Morgantown, West Virginia \\ 2005
}

Keywords: Sexually Transmitted Infections, Self-Disclosure, Health Locus of Control, Communication Anxiety, Interpersonal Trust, Personality, Conscientiousness 


\begin{abstract}
Communication Patterns Following the Acquisition of a Sexually Transmitted Infection Courtney Vail Fletcher
\end{abstract}

This study examines the relationship between personality traits and communication patterns following the contraction of a sexually transmitted infection (STI). Participants were 148 college students (46 men, 104 women) attending a large Mid-Atlantic University. Seventy-four of the participants reported having had an STI. Participants completed the Communication Competence Scale (Wiemann, 1977), the Interpersonal Trust Scale (Rotter, 1967), the Revised SelfDisclosure Scale (Wheeless \& Grotz, 1976), the conscientiousness factor of the NEO Personality Inventory (Costa \& McCrae, 1992), the Health Locus of Control Scale (Wallston, Wallston, Kaplan, \& Maides, 1976), and the interpersonal anxiety factor of the Personal Report of Communication Apprehension-24 (McCroskey, 1978). Results showed that individuals with an external health locus of control were more likely to acquire an STI; upon contraction, women were more likely to self-disclose than men; individuals with high interpersonal communication apprehension take more time to disclose; more than $70 \%$ of individuals will self-disclose within the first week following diagnosis of an STI; and the most common motivation for selfdisclosing is because the other person needed to know about the infection. Post-hoc analyses revealed that men who reported higher levels of interpersonal trust were more likely to acquire an STI and the first person most individuals tell about an STI diagnosis is either a romantic partner or a family member. 


\section{DEDICATION}

First and foremost, the author wishes to thank her committee members. You have been patient, kind, and at times, undeniable truthful with me. I am grateful for all that I have learned from you. You have set the bar high for my life and career goals.

Thanks also to my fellow masters students. My year in Morgantown would not have been the same without you. I will always carry you with me. Periodically I burst out laughing upon remembering the struggle that was to be our Master's degree.

Thanks to my mentor, Dr. Melissa Wanzer. You have changed my life and for that I am indebted to you.

Thanks to my mother, you are inspiring and truly my biggest hero. I love you.

Thanks to my father, who always makes me smile. You taught me the most important lesson in life, never stop being curious. I love you.

To my brother, I look up to you in more ways than you can know. You are such a spark and I know you will achieve such fabulous things in life. I love you.

To my favorite Aunt, god bless your heart. You are a courageous and kind woman. Never stop laughing at me, I am here to amuse you. Thank you for your undying support over the years. I love you.

To Eric Hoffberg, what to say about such a powerfully moving man. It can be summed up by saying the world just needs more people like you. Thanks for asking so many of the right questions.

Thank you to his wife Leah, my dear friend. You put the best spin on everything. Thanks for your support, kindness, and understanding. But mostly, thanks for listening even when I was not talking.

To Margey, thanks for being a non-conformist. We are just two lives that run parallel, constantly living vicariously through one another's dreams. It is through you that I can live two lives.

And thank you to Neal (and his wonderful family). You are my best friend and ultimate supporter. I will never find a better true friend and teammate. I feel blessed to have you by my side and I commend you on your magnificent sense of humor when dealing with me...I love you.

"I never stayed awake at night over a chance I took that failed but I've stayed awake over chances I didn't take." Garth Brooks 


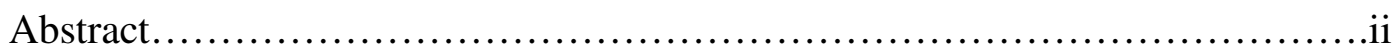

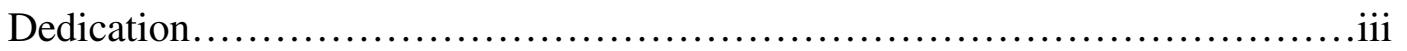

Table of Contents..................................................

\section{REVIEW OF LITERATURE...............................................................................1}

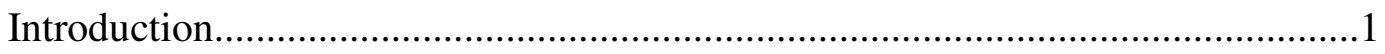

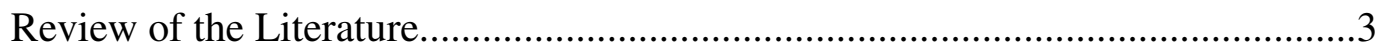

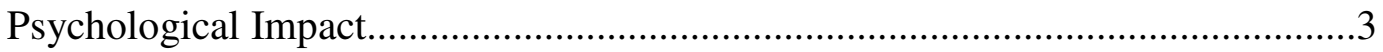

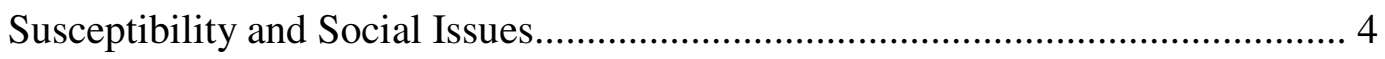

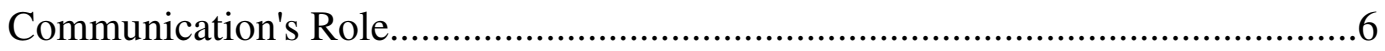

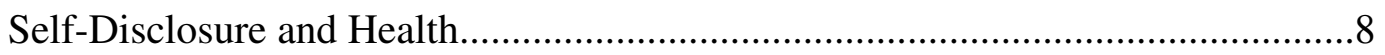

Attitudes, Knowledge, and Experience ..................................................... 12

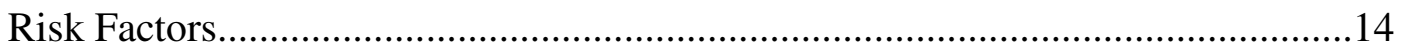

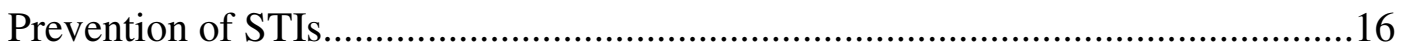

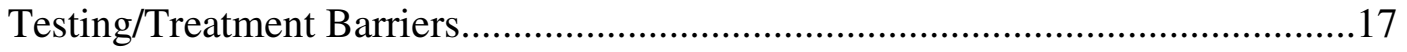

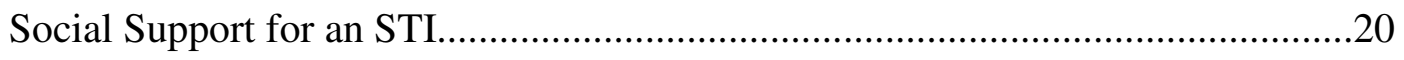

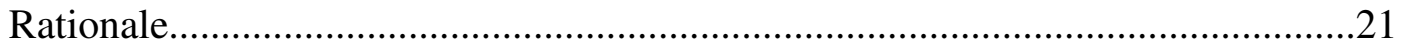

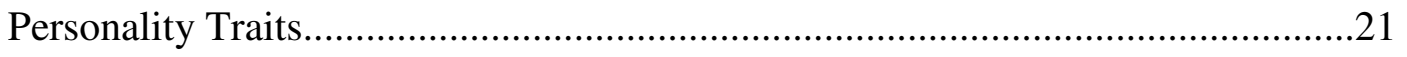

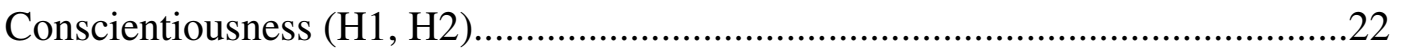

Health Locus of Control (H3, H4) ............................................................24

Sex Differences in Self-Disclosure and Social Support (H5)...........................25

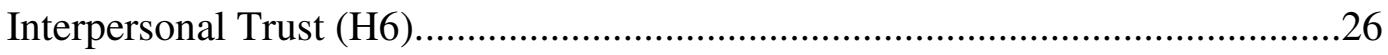


Communication Competence (H7) .................................................................2

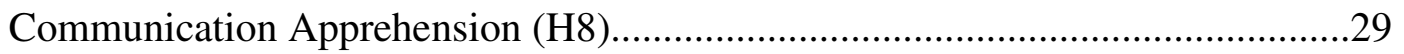

Time from Diagnosis to Disclosure (RQ1) ...........................................................

Comparison of STI Group with Non-STO Group on Personality...........................30

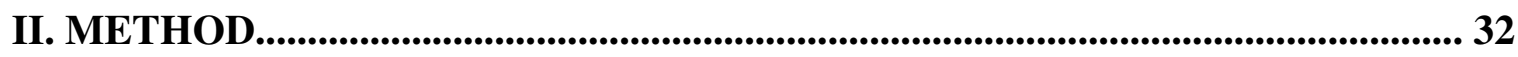

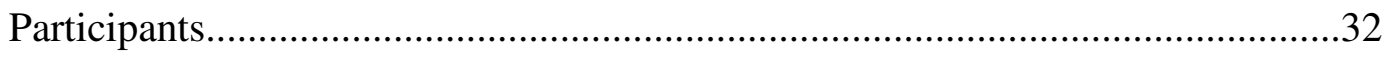

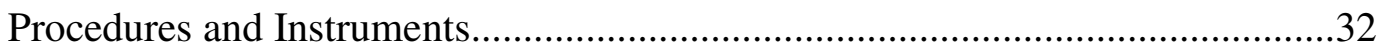

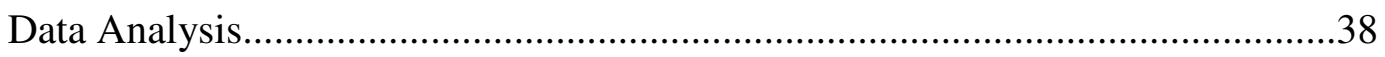

III. RESULTS....................................................................................................................................40

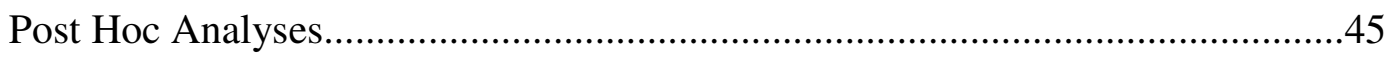

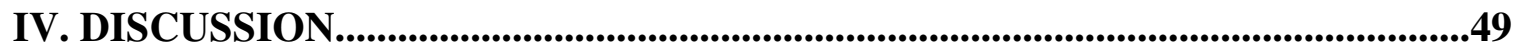

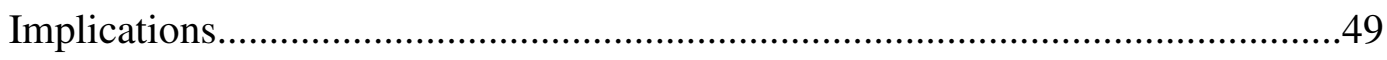

Limitations and Future Research....................................................................58

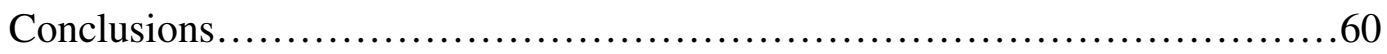

REFERENCES.................................................................................................................................61

TABLES...........................................................................................................................75

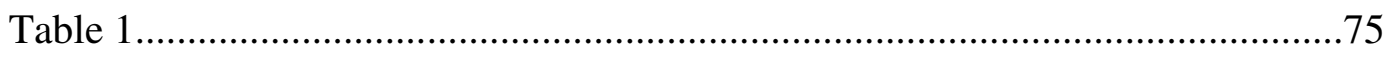

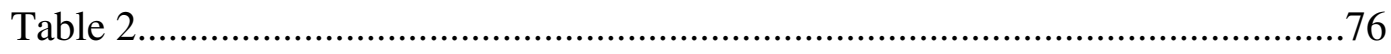

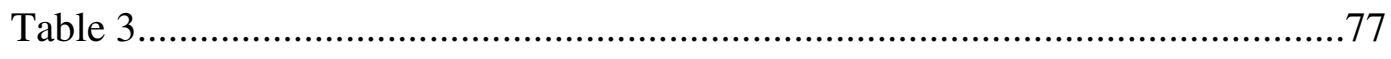

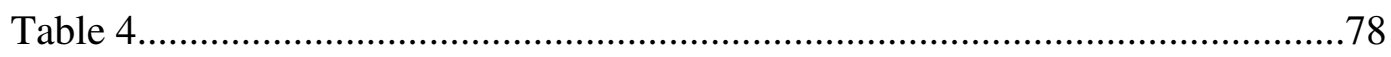

Table 5

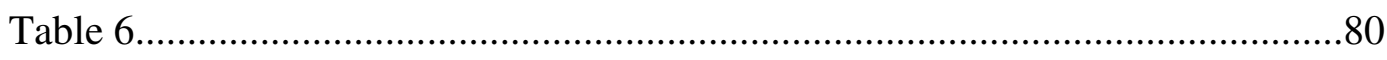

APPENDICES..................................................................................................................................81 


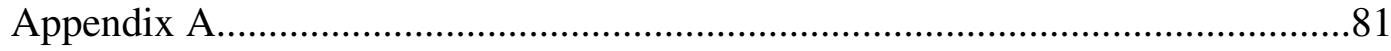

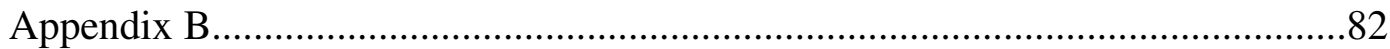

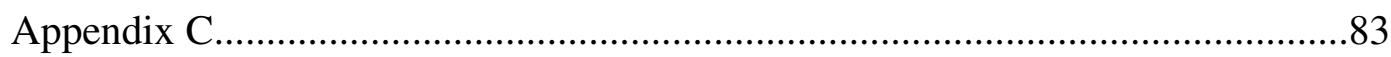

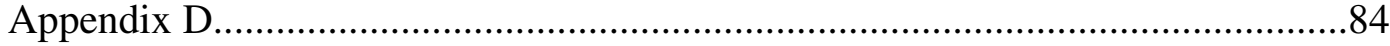

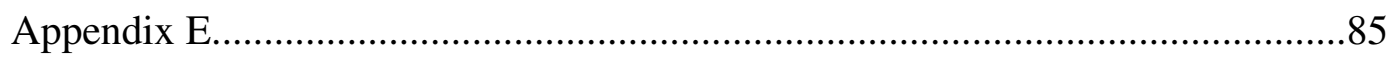

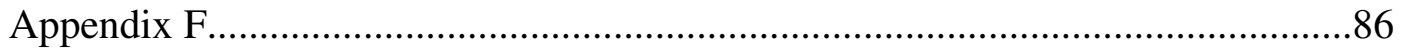

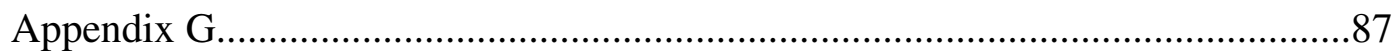

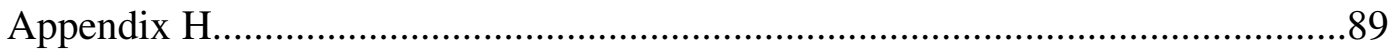


Communication Patterns Following the Acquisition of a Sexually Transmitted Infection

\section{CHAPTER 1}

\section{Introduction}

Sexually transmitted infections (STI) in the United States have been called a hidden epidemic by many health experts. The United States has the highest STI rates of any industrialized nation (The Henry J. Kaiser Family Foundation, 2000). Although 18.9 million new cases of STI are reported each year with nearly half (9.1 million) of those infected being between the ages of 15-24 (Weinstock, Berman, \& Cates, 2004), few people talk about that contraction with others in their network. In addition, this age group only accounts for $25 \%$ of the total sexually active population. This disproportionately high incidence rate of STIs in the 15 to 24 year-old age group compounds the magnitude of the epidemic and its potential harm to those infected.

Several factors contribute to such high infection rates. These factors are recognizable on biological, psychological, and cultural levels. First, lack of symptoms can play a serious role in the spread of STIs. Many STIs are asymptomatic or show no symptoms, leaving the carrier unaware of the infection and therefore allowing the infection to be inadvertently spread between individuals (Weinstock et al., 2004). The three STIs that are known for being asymptomatic and account for $88 \%$ of all new infections among this age group are: Human Papillomavirus (HPV), Trichomoniasis, and Chlamydia (Weinstock et al., 2004). Second, because prevalence rates are dramatically underestimated, only $14 \%$ of men and $8 \%$ of women believe themselves to be at risk personally. In reality, nearly half of all people who are sexually active have been infected with an STI by the time they turn 25 (The Henry J. Kaiser Family Foundation, 2000). Third, fewer than half of all adults ages 18 to 44 have ever been tested for an STI other than Human 
Immunodeficiency Virus/Acquired Immune Deficiency Syndrome (HIV/AIDS) (The Henry J. Kaiser Family Foundation, 2000). This lack of testing combined with an asymptomatic infection and a sense of invincibility contributes to the spread of STIs. Finally, another major contributor to the hidden epidemic is the negative societal outlook on STIs. More than $92 \%$ of women aged 18 to 49 feel that it would be more embarrassing to have an STI than any other health condition (The Henry J. Kaiser Family Foundation, 2003). This embarrassment alone may be the reason that individuals do not discuss their infection with others. These factors not only promote the rapid spread of STIs but also limit the ability of researchers to conduct viable research on the progression of transmissions. In order to better understand the effects of a sexually transmitted infection it is necessary to understand how an infected individual communicates interpersonally after contacting the infection.

The purpose of this study is to explore whether personality traits and sex are significant factors in one's decision to self-disclose, targets of disclosures (i.e., family member, friend, romantic partners, online support, other), and how long it takes one to disclose after obtaining an STI. Conscientiousness, locus of control, interpersonal trust, communication competence, and self-disclosure will be measured as the primary personality traits predicted to influence outcomes. In addition, a comparison between people who have, and have not, had an STI will help explore further the impact of contracting an STI on communication-related patterns.

First, a review of the literature regarding STIs and communication, specifically selfdisclosure, is presented. Second, the personality factors that may contribute to communication patterns and the acquisition of an STI is discussed, along with the corresponding hypotheses posited and the study conducted. Finally, the results of the research conducted is reported and discussed. 


\section{Review of the Literature}

The research that has been conducted regarding communication patterns following the contraction of an STI is lacking in the interpersonal communication area, yet, there is much research that has been conducted involving other areas of importance. In particular, medical research has provided a plethora of knowledge about how sexually transmitted infections can be harmful to a person's health. The Henry J. Kaiser Family Foundation (2003) reported that HPV can lead to cervical cancer; trichomoniasis may cause premature rupture of the membranes and preterm delivery in pregnant women and, if left untreated, chlamydia may lead to neonatal conjunctivitis, pneumonia, and inflammatory disease. Also, syphilis may damage internal organs, such as the brain, nerves, eyes, joints, heart, liver, bones, and blood vessels. The negative health effects contribute to an increased medical cost and help create a substantial economic burden. The total estimated health care cost to treat the 9 million new cases of STI a year in the age group of 15 to 24 is 6.5 billion dollars (Chesson, Blandford, Gift, Tao, \& Irwin, 2004). Viral STIs, such as genital herpes and HPV, account for $94 \%$ of the total cost burden while nonviral STIs, such as Chlamydia and genital warts, account for $6 \%$ of the burden. HPV and HIV are the most costly, accounting for $90 \%$ of the total medical costs of STIs in the United States (Chesson et al., 2004). The financial impact is a testament to the magnitude of this epidemic and the imperative need to understand every phase of an STI experience, including interpersonal communication patterns following acquisition.

\section{Psychological Impact}

While physical health may be the primary concern of doctors and health care professionals, STIs are also heavily correlated with serious psychological effects. Individuals between the ages of 15 and 24 perceive an STI to be a greater interpersonal problem than a 
health concern (Rosenthal \& Biro, 1995). Adolescents have more trouble dealing with the psychological aspects of the infection than any other age group. Among the top coping strategies are wishful thinking, abstinence, problem solving, and emotion regulation. However, self blame, shame, and embarrassment are often side effects of an STI and may cause deep psychological pain (Rosenthal \& Biro, 1995). Seemingly, a young adult experiencing any, if not all, of these side effects would need or want someone to talk with to help comfort him/her. On the other hand, stigma and self-blaming may depress an individual's self-disclosure about an STI.

Dibble and Swanson (2000) found that depression is commonly reported among individuals diagnosed with genital herpes. The authors' also found that, in both men and women who were diagnosed with genital herpes, there was an increase in anger and a decrease in willingness to share personal information with a stranger. Women were also found to engage in more self-concealment, display more symptoms of stress and confusion, and decreased vigor. These findings suggest that individuals diagnosed with an STI may be suffering in silence rather that self-disclosing the pain, both physical and emotional, associated with the infection.

\section{Susceptibility and Social Issues}

The age group of 18 to 24 is more susceptible to acquiring an STI than the general population for many reasons. Substance abuse is positively correlated to risky sexual behavior (Tyler, Whitbeck, Hoyt, \& Yoder, 2000). Risky sexual behavior is defined in terms of lack of condom use, having many different sexual partners in a year, and survival sex (i.e., prostitution) (Tyler et al., 2000). Also, young adults perceive themselves to be at less risk for acquiring an STI after frequency of sex with the same partner increases. Cohabitation and emotional closeness may also give false perceptions of protection against STIs (Katz, Fortenberry, Zimet, Blythe, \& Orr, 2000). 
Clearly, STIs are a dangerous problem facing American youth. Researchers have been working diligently to obtain knowledge about how to prevent the spread of STIs through educational programs. Health care professionals are continuously investigating possibilities for effective treatments of STIs through vaccines and medicines. However, it seems that one significant social barrier, above all others, may be slowing research progress. Not enough people are willing to talk about STIs in an open-minded and free manner. It is a taboo topic because of the stigma surrounding the means by which they are spread. Goffman (1963) describes a stigma as a pattern of social prejudice, discrediting, or discrimination that one endures due to others' judgments. If one reveals a concealable stigma, such as an STI, then one puts himself/herself in the position to possibly receive negative sanctions (Herek, Capitinao, \& Widaman, 2003). American culture and society has kept this epidemic hidden because of the stigma surrounding multiple sex partners. People are not even talking about STIs with their doctors. Only one out of every ten women between the ages of 18 and 44 reported talking about STIs with their health care provider during routine visits, even if infected (The Henry J. Kaiser Family Foundation, 1997). In fact, clinics may simply send home the written results from a STI screening without following up with the patient, which even further inhibits the face-to-face communication between a patient and doctor. STIs are much less likely to be discussed during a routine health exam than breast self exam, Pap smear, birth control, mammograms, alcohol use, and sexual history (The Henry J. Kaiser Family Foundation, 1997). In fact, it is seen more as a "doctors don't ask" and individuals "don't tell" scenario (p. 1). As a result, it appears as if the public in general does not fully understand or appreciate the seriousness of an STI. 


\section{Communication's Role}

Not communicating about STIs with a healthcare provider may be one leading cause of the lack of knowledge and consequently the spread of STIs. According to the Henry J. Kaiser Family Foundation (2000), most people do not talk about STIs even with their sexual partner. For example, only about one quarter (27\%) of American women reported talking about the risks associated with an STI with a partner. Moreover, almost all of the women (98\%) who stated that they had never discussed STIs with their partner also reported that their partner has never been infected with an STI. Yet, 14\% of women who have had a conversation with their partner about STIs report that their partner has had an STI at one time. These statistics point out a substantive difference between individuals' beliefs and reality. Also, almost half of women (46\%) who have had an STI have never discussed STIs with their current or former partners. The lack of discussion about STIs between sexual partners arouses a pertinent question. Why should individuals discuss STI's? It could be suggested that open communication about STIs may help decrease the stigma surrounding STIs and perhaps slow or prevent their spread.

Communication does not always bring positive results; in fact, communication scholars claim that too much communication may be harmful (Booth-Butterfield, 2002). For example, if an individual were to share his/her experience with a friend and that friend told others, then more psychological harm may be caused due to the stigma. Therefore, a lack of interpersonal communication is potentially detrimental to all involved if it means that the infections will spread more rapidly or emotional support can not be provided.

What is not fully understood is whether young adults who know they are infected with an STI are willing to talk about that STI with anyone, not for treatment alone, but for simple emotional and psychological comfort. The American Social Health Association website lists 
instructions on why to tell a partner if you have an STI, when to tell a partner, how to tell, and how a partner may react (www.ashastd.org). For example, it is suggested that an infected individual should tell their partner about their infection before becoming sexually active. Also, when disclosing an STI to a partner, the infected individual should be prepared with facts and literature (e.g.., brochures) for their partner to read. In addition, the website states that one should expect a positive reaction in most cases after disclosing to a partner about an STI. Yet, there are exceptions, and in the instance of a negative response, it is important for the individual to reassess how this negative reaction may be a deeper sign of their partner's inability to be a supportive mate. But are young adults suffering alone? Are individuals who have contracted an STI failing to self-disclose due to a fear of negative repercussions? A realistic goal for health education programs may be teaching individuals how to communicate and seek help following the acquisition of an STI.

Researchers have investigated many facets of the sexually transmitted infection epidemic. It seems that research has focused heavily on areas of prevention, treatment, risks, and attitudes, knowledge, and experience towards STIs. Yet, little research has focused on the rapidly growing population of young adults infected with STIs (i.e., 9 million new cases in U.S. alone in this age group) and their communication with others about their STI. Much more information is needed to fully understand the pressures, risks, and influences facing young adults before any real progress can be made (The Henry J. Kaiser Family Foundation, 2003). Wilson (2000) set forth an entire agenda toward educating youth about sexual health by the year 2010 . The agenda was based upon prior research from government agencies, schools, and Planned Parenthood. This agenda suggested that the state of sexual education in the United States currently is inadequate 
considering that $65 \%$ of teenagers are sexually active before they graduate high school (Wilson, 2000).

In the past, STI research often focused on investigating the most effective method of getting information out to the general public about STIs. If individuals are not receiving information about STIs from their healthcare providers or their partners, then where are they turning for their knowledge? In a news release by The Henry J. Kaiser Family Foundation (2001), it was reported that young adults are not only using the internet as a source to shop, email, chat with friends, and download music, but also as a source of gathering health information. As many as two out of three young adults have cited that the internet, instead of parents, friends, or health professionals, is where they are seeking health information. Magazines, due to their anonymity, have also been a large provider of sexual information for young adults with magazines like Cosmopolitan, Self, and Glamour being primary sources for many (Walsh-Childers, 1997). Yet, the information obtained from a magazine may be outdated and feedback may be slow coming. Therefore, despite gaining information from the internet, magazines, and health campaigns, young adults may still be misinformed and/or under informed or psychologically isolated. As a consequence of the lack of information dissemination, young adults may feel pressure to keep quiet about STIs (The Henry J. Kaiser Family Foundation, 2003)

\section{Self-Disclosure and Health}

The decision to self-disclose about an STI may be a difficult and stressful one. "Selfdisclosure is a process whereby one person verbally reveals private thoughts, feelings, beliefs, or attitudes to another person "(Vogel \& Wester, 2003, p. 351). Research has suggested that selfdisclosing to others may be directly related to one's physical health. Also, it has been found that 
self-disclosure is highly related to personality traits (Linying, 2003). More specifically, an individual who is more extroverted is more likely to self-disclose, and self-disclosure is negatively related to loneliness and depressive moods (Linying, 2003). Simoni et al. (1995) found that individuals will not disclose about HIV to family, friends, and partners due to fear of rejection, to maintain secrecy, to avoid consequences associated with a negative stigma, and because of others' ignorance. However, it was found that actual reactions to an HIV disclosure were found to be generally supportive.

The importance of self-disclosing and/or talking about traumatic life events has been thoroughly researched in several other health-related arenas, specifically in the rape/sexual assault literature. According to Siegel, Sorenson, Golding, Burnam, and Stein (1989) considerable amounts of research has supported that self-disclosure and talking about a stressful event in an individuals' life is extremely helpful in the coping process. The authors conducted a study to determine the use and helpfulness of seeking support after a sexual assaulted. Of the randomly surveyed respondents who reported having been sexually assault $(n=447)$, two-thirds had disclosed to someone about the assault. The target of disclosure varied with friend or relative (59.3\%), police (10.5\%), and mental health professional (16.1\%) being the top three targets. Nearly three-fourths (73.8\%) of those who made the decision to disclose found at least one person helpful.

In another study, the profound negative health consequence for victims' emotional and physical well-being after a sexual assault was investigated (Mcauslan, 1999). The study focused on two factors thought to moderate the impact of sexual assault on victims' well-being: disclosure and the reactions received from others. The study was guided by two theoretical perspectives regarding the relationship between disclosure and health: psychosomatic theory of 
inhibition and social support theory. The psychosomatic theory of inhibition focuses on the relationship between the inhibition of strong emotion and the development of physical disease (Watson \& Pennebaker, 1989). The social support theory states that disclosure of a traumatic experience, such as sexual assault, is a means of mobilizing social support (Pearlin \& McCall, 1990). The results indicated that upon self-disclosure, positive social reactions were found to be unrelated to health; yet, negative social reactions were found to be a strong predictor of negative health. Despite the evidence that self-disclosure may be harmful for one's health, especially if a negative response is received, overall, more support is found for the positive effects of selfdisclosure. For example, Routbort (1998) explored the positive outcomes associated with a women's disclosure to others about a personal experience with rape. Eighty-seven women who had been sexually assaulted in the last five years were included in the study. The results indicated that higher levels of general social support were positively correlated with better recovery and those women who reported having talked more freely about the assault evidenced fewer symptoms (i.e., depression, self-blame, self-esteem). The women in the study also reported generally supportive self-disclosure experiences, both immediately following the rape and subsequently.

What may be the determining factor that predicts whether an individual will self-disclose about an STI is the individual's anticipated utility or anticipated risk associated with the selfdisclosure. Anticipated utility is the perceived value of the outcome to the individual who is selfdisclosing. Does the person believe that seeking support is effective and useful? Anticipated risk is the individual's perception of the possible risks associated with self-disclosing about an STI. More specifically, an individual may fear being judged, misunderstood, or vulnerable. Men, in particular, tend to not want to compromise society's gender based expectations associated with 
asking for help (Vogel \& Wester, 2003). Positive reactions or feedback from the target of selfdisclosure is an important factor in the determining if seeking social support will be useful or helpful. In regard to feedback during a self-disclosure of a report of child abuse, Jonzon and Linblad (2005) reported that a positive reaction from a partner was related to fewer symptoms, whereas negative reactions were found to be negatively correlated with emotional well-being.

Keller, Sadovsky, Pankratz, and Hermsen (2000) investigated self-disclosure of HPV to sexual partners and found that there was no relationship between transmission knowledge and disclosure beliefs. Participants reported that, although they would disclose to sexual partners at the time of diagnosis, they would not disclose to new partners six months later. The authors added that fear of stigmatization and discrimination, disruption of relationships, not wanting to worry others, loss of financial support, and emotional self-protection (i.e., feelings of isolation, loneliness, shame, embarrassment) were the biggest factors in participants not wanting to disclose about being HPV infected. Also highlighted was that disclosures may be highly linked to the level of intimacy in the relationship. Interestingly, $30 \%$ of participants were either unsure or did not believe that they had a responsibility to tell their casual sexual partners about their HPV.

In support of the notion that self-disclosures may be highly linked to level of intimacy within the relationship, Sprecher and Hendrick (2004) stated that relationship quality (i.e., satisfaction, love, and commitment) was positively correlated to self-disclosure. Also, while it is typically thought that women self-disclose more than men, new research has found that men and women self-disclose at about the same level. What may be likely is that personality differences are more highly associated with an individual's tendency to self-disclose than sex (Sprecher \& Hendrick, 2004). For example, it has been found that individuals with higher self-esteem are 
more likely to self-disclose. Also, being the receiver of a self-disclosure has been found to increase one's self esteem. Manne et al. (2004) reported that breast cancer patients were able to increase their intimacy levels with relational partners through self-disclosure, resulting in the strengthening of the relationship. The strengthening of a relationship as a result of self-disclosure may help build trust and security. This in return may provide the confidence necessary to communicate openly about intimate topics, such as STIs.

Agne, Thompson, and Cusella (2000) reported that HIV positive patients self-disclose to others about their condition if they perceived a necessity for the disclosure, felt comfortable with the self-disclosure (i.e., person, timing), and if the risks for stigmatization were minimal. Stigmatized persons are evaluated negatively by others. It is primarily a perception or receiver based variable in which an attribute is inconsistent with conceptions of normality and it is often discrediting. Self-disclosure of a sensitive and personal topic may be help an individual manage the potentially harmful effects of stigmatization (Agne et al., 2000). Nonetheless, the selfdisclosure about an STI to another person is risky and, in many instances, potentially harmful. Yet, the research finds that the need for understanding, compassion, and maintaining a healthy self-esteem, may be worth the risk.

Attitudes, Knowledge, and Experience

Misconceptions about sexual health are a primary factor in the spread of STIs in the United States. Adolescents are experimenting with sexual activity at an increasingly younger age while their knowledge about sexual consequences continues to be inadequate (The Henry J. Kaiser Family Foundation, 2001), a potentially lethal combination. The Henry J. Kaiser Family Foundation released the results of a nationwide survey investigating young adults' knowledge, attitudes, and experiences with sexual health in 2003. The key findings can be summarized as 
follows: sexual issues (e.g., pregnancy, HIV/AIDS, STIs) dominate their concerns; they report considerable pressure to have sex; one in five is unaware that oral sex can transmit STIs; many are reluctant to discuss sexual health issues with partners, family, and health care providers; alcohol and drugs often play a dangerous role in their sex lives; many report misconceptions about STIs and are misinformed about safer sex options; they mistakenly believe that they are naturally tested for STIs as part of their routine health exam; sex without a condom is risky but not a essential; and using a condom can be a sign of mistrust and suspicion. Most notable to this research project is young adults' reluctance to discuss health issues with partners, family, or health care providers. What is the underlying cause of this reluctance? It may be the stigma surrounding STIs, the fear of societal consequences, or maybe the lack of interpersonal trust that keeps individuals from communicating about STIs with anyone.

Another cause of misconceptions about STIs is that adults tend to assume that teenagers and young adults know a lot of information about sex and sexually related topics, when in fact they are quite unaware (Carrera, Kaye, Philliber, \& West, 2000). Adults' reference increased sexuality in the movies, music, and TV as providing evidence that young adults have a surplus of knowledge on topics involving sex. In fact, young adults' insufficient knowledge regarding sexual health issues is apparent through STI prevalence rates alone (Carrera et al., 2000). Other studies suggest that there has been an increase in knowledge and condom use, which leads researchers to believe that health education programs have had a positive impact. However, much research is inconclusive (Pluhar, Frongillo, Stycos, \& Dempster-McCain, 2003). Murphey and Nagy (2002) reported that over a ten-year period of time STI knowledge has increased among 15 and 16 year olds. Nonetheless, STI rates continue to increase among this age group. Once again, the lack of knowledge regarding STIs and negative attitudes (i.e., stigmatization) 
could potentially be combated through positive interpersonal communication experiences, specifically self-disclosures by those infected with an STI. If individuals in the United States were encouraged to be honest and open with questions and concerns regarding sexual health then it may foster a more supportive environment for those who have contracted an STI to disclose about their experience. In return for the open acceptance of infected individuals' disclosures, society may become better equipped to deal and understand the potential risks associated with risky sexual behaviors. Also, as a benefit to those infected, stigmatization may be lessened.

\section{Risk Factors}

The risks factors for obtaining an STI are easily described. Alcohol use, which leads to engagement in risky sexual behaviors, lack of condom use, and misinformation about STIs are the leading risks facing young adults between the ages of 18 and 24. Kelley, Borawski, Flocke, and Keen (2003) investigated teenagers who were engaging in sequential (not overlapping in time) and concurrent (overlapping in time) sexual relationships. They found that teens in sequential and concurrent relationships reported a higher degree of regret about the sex due to alcohol and lower usage of condoms. This behavior leads to a higher risk of STIs in comparison to individuals who are single and do not engage in similar behaviors. Corbin and Fromme (2002) reported that alcohol use is the largest risk factor for contracting an STI in the initial stages of a relationship, whereas familiarity and alternative contraceptive (e.g., birth control) become the greater risk factor as the relationship advances. Ericksen and Trocki (1994) illustrated many

potential risks associated with STIs by conducting a national sex survey. The authors found that women become infected with an STI more readily than men because of physiology, despite having fewer sexual partners and beginning sexual activity later in life. Once infected, women 
also stay infected longer. Problem drinking and young age are among the largest risk factors for women (Ericksen \& Trocki, 1994).

Sexual orientation was reported as the most important risk factor for men, with $34 \%$ of gays and bisexuals and 9\% of heterosexuals having had at least one STI. The high STI prevalence rate for gay and bisexual men can be attributed to several common factors emerging within these communities. Carballo-Dieguez (2001) reported that although the risk of transmission of STIs may be minimized with consistent condom use, many gay and bisexual men find it difficult to uphold this practice. Also, it has been found that gay men have a history of multiple partnerships and may engage more frequently in sexually activity. The sex differences found in risk factors may also suggest that there will be sex differences in reasons for disclosing to another and who one discloses to regarding their STI.

College campuses are a common place that many individuals face the risk factors associated with the acquisition of an STI. A study conducted on a college campus reported an overall STI prevalence rate of $13 \%$ (Kotloff et al., 1991). Ninety percent of college students are sexually active with many having multiple, serious sexual partners at one time while only $18 \%$ of college men and $13 \%$ of college women reported using condoms consistently (Corbin \& Fromme, 2002). The age group that is at the highest risk could lower their risks dramatically if people could understand how important communication and disclosure can be in stopping the spread of STIs. After contracting an STI, a person's greatest need for communication may be to obtain a cure, medicinal treatment, or emotional support. Yet, in order to decrease future infections, one should always communicate with sexual partners about STIs before engaging in sexual activity. 


\section{Prevention of STIS}

Bradner, $\mathrm{Ku}$, and Lindberg (2000) state that "more prevention efforts need to be aimed at young adults" (p. 33). Many prevention and intervention efforts have been made to stop the increase of STIs. Researchers spend millions of dollars every year to find the most effective methods to stall or stop the spread of STIs with mixed success rates (Rickert et al., 1993). Rickert et al. (1993) identified the persons that are at the highest risk for contracting a STI and developed an intensive intervention program aimed at these persons. As a result of this study, it was concluded that targeting high risk populations through health/information campaigns would be the most appropriate course of action. Maher, Peterman, Osewe, Odusanya, and Scerba (2003) reported that an intensive one-year counseling intervention did not reduce STI acquisition. Portner (1996) recommends that age-appropriate health services, education, access to condoms, and clinical services should be used to help prevent, diagnose, and treat STIs. Increasing public awareness and changing behavior patterns over a prolonged period of time are also highly recommended (Portner, 1996). Gerbase, Noriega-Minichiello, and Vuylsteke (1998) state that young adults, aged 15 to 24, are at an even greater risk for contracting an STI due to their inability to say no to unsafe sex. The authors suggested that prevention attempts should be aimed at prevention campaigns that are set forth not only by health care providers but by private sectors as well. This proposed study would be an example of research that could potentially further the knowledge regarding how to reach young adults more effectively through interpersonal communication.

The Center for Disease Control and Prevention (CDC; 2003) conducted a study to find the most effective way to prevent the spread of STIs in the United States. Its conclusion stated that individuals should abstain from sex or only engage in a long-term, mutually monogamous 
relationship with a partner who has been tested for STIs, and who one knows is uninfected. But asking young adults to abstain may be unreasonable and/or naive. It is already known that most young adults are having sexual intercourse before they leave their teens. For persons unwilling to abstain or maintain long-term monogamous relationships, correct and consistent use of latex condoms should be used to reduce the risk of contracting an STI. Still, no protective method is $100 \%$ reliable and effective. The research conducted relating to prevention of STIs does not mention the possible advantages and benefits that word of mouth or interpersonal communication could have on slowing or preventing the spread of STIs. Betts (2002) suggested that talking openly and honestly with sex partners and medical care providers about sexual health issues may help decrease STI infection rates. In another study, lack of interpersonal communication was found to be significantly associated with lower odds of condom use, communication with parents about STI prevention, recent sex with a partner who was not a boyfriend/girlfriend, and low motivation to use condoms (Crosby, Sanders, Yarber, Graham, \& Dodge, 2002). The authors suggested that given the importance of interpersonal communication in promoting safer sex behaviors, STI prevention programs may benefit adolescents by addressing the benefits of interpersonal communication about sexual health issues (Crosby et al., 2002). Implementing health communication classes in which students would learn how to better communicate about health and/or health risks with others could be considered a viable method of prevention. Sex education classes are the closest match to this concept, yet they may not be teaching young adults how/why/when to communicate about STIs with others interpersonally.

\section{Testing/Treatment Barriers}

Many barriers keep individuals from seeking the proper healthcare for STIs, which increases STI infection rates dramatically. Fortenberry (1997) reported that symptomatic females 
take the longest time to seek treatment for an STI, maybe due to embarrassment or shame. The factors that contribute to a longer duration of time between awareness of symptoms and careseeking included perceptions of care barrier, stigma, greater perceived seriousness of STIs, lower self-efficacy for response to an STI, and previous history of a STI. Widespread testing for STIs is constricted due to limited access to proper healthcare (Todd, Haase, \& Stoner, 2001). Emergency rooms have detected a large number of asymptomatic STIs in the course of testing for other conditions (Todd et al., 2001). Yet, most individuals who are aware of their STI, report going to a private practice for testing while only $5 \%$ report attending a clinic (although men were more likely to go to a clinic than women) (Brackbill, Sternberg, \& Fishbein, 1999). Overall, healthcare seeking strategies of STI treatment in the United State are complex. Specific disease diagnosis, sex, race, and income status all play a role in where people seek help (Brackbill et al., 1999). Hence, any research initiatives should take this into consideration. Cohen and Nsuami (1999) reported that repeated testing, treatment, and counseling in school settings are linked to reductions in STIs in boys only. Once again, physiology and lack of communication puts girls at a disadvantage for contracting and carrying an STI.

Research has informed health care professionals, as well as the general public, about STIs. The major link missing appears to be communication. At all stages of prevention, testing, treatment, attitudes, and information gaining, communication seems to be deficient. There have been several attempts to educate the public about how to communicate and approach sexual health issues. For example, the Parent-Adolescent Relationship Education (PARE) Program was implemented in a middle school setting as a means of educating students and their parents about the importance of family communication regarding sexual issues (Lederman \& Mian, 2003). The program focused on various behaviors to help prevent teen pregnancy, HIV, and STIs. In 
addition, the course aimed to enhance decision-making, refusal, and resistance skills to unsafe sex or risky sexual behavior. Still, despite the attempts of resistance programs, there is a portion of the research that seems to be nonexistent altogether. Who are the individuals to have contracted an STI talking to about their experience, not for purposes of treatment but for emotional support or to relieve psychological pain? Social stigmas and negative consequences associated with STIs alone represent significant barriers to visiting healthcare providers for testing, treatment, or psychological counseling (Barth, Cook, Downs, Switzer, \& Fischhoff, 2002). In fact, results of a study conducted by Barth et al. (2002) suggested that increased interpersonal communication about STIs could be a significant benefit to decreasing their spread. Furthermore, the authors stated that the increase of interpersonal communication may allow discomforting topics, such as STIs, to become more mainstream in society and, therefore, more acceptable to talk about. In addition, increased interpersonal communication about STIs may allow for the correct information regarding sexual health to become more readily available to the public. If individuals become more equipped with the correct knowledge about the consequences of risky sexual behavior, they may be less likely to engage in risky behaviors, such as unprotected sex, which increases the spread of STIs. However, stigmatization and information gaps seem to be serious impediments to interpersonal communication because they do not promote the positive environment needed for individuals to communicate about sexual health.

Another factor contributing to the incidence of STIs is that individuals, rather than talk about STIs, rely on stereotypes to assess who may have an STI. Zaromatidis, Carlo, and Racanello (2004) found that people associated high sensation seeking males as being the most likely carrier of an STI. This perception has never been validated other than to say that risk taking men (e.g., sky divers, rock climbers) may be more likely to engage in risky sexual 
behavior as well. Stanton et al, (1999) supported the research that found that high sensation seekers have increased HIV/AIDS infection rates.

Social Support for an STI

In times of trouble or despair, individuals often seek out others for support, which may necessitate a conversation between at least two people. Contracting a sexually transmitted infection would be, for many, a time when emotional support would be needed. Shumaker and Brownell (1984) defined social support as "an exchange of resources between at least two individuals perceived by the provider or recipient to be intended to enhance the well-being of the recipient" (p. 31). One function of social support is emotional support: the expression of concern, sympathy, compassion, and esteem for an individual (Shaw, Krause, Chatters, Connell, \& Ingersoll-Dayton, 2004). When deciding whether to seek support, an individual must make a decision about whether the costs (e.g., embarrassment, threat to self-esteem) outweigh the benefits (e.g., more effective coping) (Hill, 1991). Deciding whether to seek support is more complex than just whether help is available. Ong and Weiss (2000) reported that privacy is an important issue when seeking emotional support for a socially unacceptable situation. When one feels that his/her anonymity and confidentiality may be threatened, he/she may not seek social support.

The benefits of social support are important for an individual's health and well being (Shaw et al., 2004). Umberson (1987) reported that social support facilitated health promoting behaviors, such as healthy diet, exercise, adequate amounts of sleep, and appropriate use of alcohol and cigarettes. Uchino, Cacioppo, and Kiecolt-Glaser (1996) stated that social support facilitates recovery from or an adjustment to a disease. The positive effects of social and emotional support may never be felt by individuals suffering from an STI. Green (2002) reported 
that the embarrassment related to STIs may be the leading factor that prevents infected individuals from seeking emotional support from others. At the time of life that young adults are at highest risk for infection, emotional factors may also have the strongest potential impact (Whitten, Rein, Land, Reppucci, \& Turkheimer, 2003).

Sex differences in emotional support seeking also play an important role. Research suggests that men and women may have different perceptions of what constitutes support (Flaherty \& Richman, 1989). Women more than men seek emotional support during times of distress (Burleson, 2002). But what personality traits, if any, contribute to or detract from seeking support or self disclosing to others about the contraction of an STI? It is important to evaluate the role that individual personality traits may play in one's decision to disclose about a STI.

\section{Rationale}

\section{Personality Traits}

Rudd (2003) suggested that personality traits are important to investigate because they provide a link to understanding individuals' behavior and can be predictive of severe behaviors, such as suicide. For example, individuals' with high self-esteem report themselves positively on several personality traits that have been found to be negatively associated with subsequent perceptions of vulnerability to sexually transmitted diseases. In this particular study, the authors suggested that young people, especially individuals who have high self-esteem, tend to resist acknowledging information that they may find threatening and, as a result, may engage in a variety of strategies to avoid it (Boney-McCoy, Gibbons, \& Gerrard, 1999). Moffett, Steinberg, and Rohde (1996) suggested that an individuals' behavior can be best understood as an interaction of his/her personality. Furthermore, approximately 45 studies were reviewed from 
1928 to 1991 during which several psychosocial variables, such as personality traits, stress, emotional distress, attributions, and social support, were examined to determine there impact on coping with genital herpes. Personality traits, such as anxiety, were found to be an important factor in the prediction, maintenance, and management of recurrent genital herpes, as well as, the extent of the impact of the stressor on the individual emotionally (Valois, Oeltmann, Waller, \& Hussey, 1999). In another study, that assessed psychosocial and demographic predictors of safer anal intercourse among gay men, the authors concluded by suggesting that personality traits that determine a level of commitment to behavior change, tendencies to take risks, and age need to be considered when designing effective HIV prevention interventions (DiFranceisco, Ostrow, Adib, Chmiel, \& Hoffman, 1999).

\section{Conscientiousness}

Individuals who are conscientious may be less likely to acquire an STI but will be more likely to deal with it effectively. Conscientiousness is part of the big five taxonomy of personality traits with the other four traits being agreeableness, emotional stability, openness to experience, and introversion-extraversion (Costa \& McCrae, 1992). Conscientiousness refers to an individual's propensity to be goal and task directed, to delay gratification, to plan, to be dutiful, and to be responsible (Bogg \& Roberts, 2004). The more conscientious a person is, the more competent, dutiful, orderly, responsible, and thorough they act (Costa \& McCrae, 1992). It has been suggested that variations in an individuals' level of conscientiousness are due to a child's early social interactions with their environment and subsequent internalization (Hogan \& Ones, 1997). Much research has explored conscientiousness and its relationship to several constructs, but its significant relationship to various health scenarios has been widely accepted and thoroughly supported. 
It has been identified as an important health-related trait mainly because individuals that are high in conscientiousness are less likely to let their health become poor (Bogg \& Roberts, 2004). More specifically, many studies have explored the relationship between the conscientiousness personality trait and health behaviors. For example, Soane (2005) found that when making decisions about one's health, individuals who have higher levels of conscientiousness make more consistent and thorough decisions. Knoll, Rieckmann, Scolz, and Schwarzer (2004) stated that conscientious individuals might feel especially inclined to report better overall health, even when living a stressful lifestyle. Furthermore, conscientious individuals are more inclined to underreport difficulties when faced with a challenge. Conscientiousness has significant and life-long implications for individuals. It has been found that when conscientiousness was assessed during childhood, researchers could predict longevity in adulthood. More specifically, conscientious individuals were found to have a 30\% lower mortality risk than low conscientious individuals (Friedman et al., 1995). However, Friedman et al. (1995) did acknowledge that while life-long health behaviors accounted for a large part of the decreased mortality risks, there are still unexplored variables. Contrada, Cather, and O'Leary (1999) state that one's behaviors should play a significant role in mediating the relationship between personality and disease; conscientiousness has been shown to have an effect on behaviors related to risky sexual behaviors, as well as, illicit drug use and cardiovascular health (such as tobacco consumption, exercise, and healthy eating). Based on this reasoning, the following hypotheses were posited:

H1: Among individuals who have had an STI, those who have self-disclosed about their STI will have higher conscientiousness scores than will those who have not self-disclosed about their STI. 
H2: Individuals who have had an STI will have lower conscientiousness scores than will individuals who have not had an STI.

\section{Health Locus of Control (HLOC)}

The health locus of control construct is derived from the Social Learning Theory. This theory states that individuals learn how to act or behave based on how their behaviors have been reinforced in the past or via observation of others reinforcement (Lau, 1982). As a result, an individual will develop general and specific expectancies about what rewards or consequences one will receive for a specific action or behavior. Through this learning process individuals develop either an internal or external locus of control. Individuals who believe that health is a function of personal behavior (internal locus of control) have been shown to take greater responsibility for their health (e.g., engage in more preventive behaviors) than those with an external locus of control. Individuals with an external locus of control believe that their health is a function of luck/chance or determined by powerful others such as doctors, other health professionals, and family members (Wallston \& Wallston, 1981). External LOC has been associated with fewer problem-focused coping behaviors and higher levels of perceived illness (Horner, 1996). Based on this reasoning, the following hypotheses were posited:

H3: Among individuals who have had an STI, those who self-disclosed about their STI will have a higher internal health locus of control scores than those who have not selfdisclosed about their STI.

H4: Individuals who have had an STI will have higher external locus of control scores than will individuals who have not had an STI. 


\section{Sex Differences in Self-Disclosure and Social Support}

What compels one to share her/his secrets with others? Relationships that are developed between two acquaintances are characterized by the information exchange that takes place. Each person divulges information about oneself in an attempt to develop the relationship further (Shaffer \& Ogden, 1986). The process of self-disclosing has been described by communication scholars as being analogous to peeling an onion. As two individuals get to know each other better, they peel back a layer of the onion with each deeper level they reach (West \& Turner, 2003). Self-disclosure can also be awkward, especially for someone who has a STI because of the stigma surrounding STIs. If one reveals a concealable stigma, such as an STI, then one puts himself/herself in the position to possibly receive negative sanctions (Herek, 1997). Relating to the sense of duty evident in individuals high in trait conscientiousness, many individuals decide to self-disclose despite risk of negative sanctions as a means of advocating the issue and helping to change society's attitude (Herek, 1997).

Dindia and Allen (1992) stated in a meta-analysis that self-disclosure has been identified as a stable personality trait that is heavily related to one's sex. It appears that the male sex role requires a man to appear tough, achieving, unsentimental, and emotionally unexpressive (Dindia \& Allen, 1992). Dindia and Allen also state that males disclose less than females about health issues in particular. Shaffer and Ogden (1986) reported that females self-disclose more than males on every topic overall. Stokes (1987) stated that that displaying a willingness to selfdisclose may be beneficial to one's social life and interpersonal relationships. On the other hand, a person who consistently does not self-disclose is more likely to be lonely and feel socially isolated. Keller et al. (2000) reported that women may be less likely to disclose an STI to a sexual partner due to the distribution of power in the relationship, which is in the men's favor. 
Furthermore, in the American culture, women are at a greater risk of being stigmatized due to this inequality of power and lack of knowledge. Still, the preponderance of research has supported the pattern that women seek social support and self-disclose more often than men. Based on this reasoning, the following hypothesis was posited:

H5: Women are more likely than men to self-disclose about their STI.

\section{Interpersonal Trust}

The concept behind who we trust and why we trust them can be complicated. In the current study, participants' interpersonal trust was examined from a trait perspective. More clearly, while individuals' level of trust may change in various situations, ultimately, individuals maintain a certain level of trust overall. For example, an individual may be untrusting of passing a stranger in a dark alley at night; yet, this same individual may trust a stranger to watch a bag at the airport. Both examples are situational, yet, this study is interested in investigating individuals' overall trust or predisposition towards trusting others. Interpersonal trust can be described as the view that the other person in the relationship (e.g., friend, family member, romantic partner) will not engage in any behavior/action that has potential to do harm (Rotter, 1967). It has also been described as the feeling that one can depend upon that other person to meet his/her expectations when one is not able to control the other person's behavior (Brothers, 1995). Ultimately, interpersonal trust involves one person allowing herself/himself to be vulnerable to another person's behavior or actions. In the instance of self-disclosing to another about an acquired STI, the presence of interpersonal trust is crucial. It would seem that the risks of others discovering this private information, who were not intended to, would lead to heightened skepticism about whom one can truly trust. The psychological damage of the stigma surrounding STIs would seemingly be sufficient to keep the information to oneself. It has been 
found that trust affects a patients' willingness to seek care, reveal sensitive information, receive treatment, and follow physicians' recommendations (Hall, Dugan, Zheng, \& Mishra, 2001). Yet, there are positive effects of disclosing to someone trustworthy. It has been found that high levels of interpersonal trust within a family has been solely responsible for helping members during times of suffering or stress and keeping children from engaging in deviant behavior (Rotter, 1967). Brothers (1995) stated that a person's self-esteem, security, and well being may be dependent on the giving and receiving of trust from/with others. Based on this reasoning, the following hypothesis was posited:

H6: Among individuals who have had an STI, those who have self-disclosed about their STI will have higher interpersonal trust scores than will those who have not selfdisclosed about their STI.

\section{Communication Competence}

What if an individual feels as if he/she is not successful in his/her communication with others? This person may be lacking communication competence, "the degree to which individuals satisfy and perceive that they have satisfied their goals within the limits of a given social situation without jeopardizing their ability or opportunity to pursue their other subjectively more important goals" (Parks, 1994, p. 595). In a clearer description, Spitzberg and Cupach (1984) state that competent communicators are perceived as being motivated to communicate, knowledgeable about how to communicate, capable of utilizing their knowledge, sensitive to the communication content, and capable of achieving outcomes in their communication interactions. In the past, researchers have tried to conceptualize communication competence in a variety of different ways, focusing on several different variables. However, many researchers agree that 
there are three main elements of communication competence: cognitive, affective, and psychomotor (Duran \& Spitzberg, 1995).

The common theme found in communication competence is effectiveness. After acquiring an STI, a person who believes that he/she is lacking in the skills necessary to send an effective message to another and handle the response may not even attempt that communication. Another factor affecting the overall success of a competent communication situation may be anxiety or uncertainty. Anxiety/Uncertainty Management theory (AUM) states that communicators need to manage their uncertainty (e.g., individuals' inability to predict others' behavior) and anxiety (e.g., feeling uneasy about what might happen) for effective communication to occur (Gudykunst, 1995). Uncertainty and an individual's lack of the skills needed to manage uncertainty/anxiety may have serious health implications. Brashers (2001) stated that recent disease prevention practices help illustrate how American culture has become obsessed with illness. For example, continuous health surveillance and constantly improved upon methods for screening and monitoring disease and illness, nearly guarantees that healthcare professionals will find something wrong with every individual. As a result, a society is created that is seemingly chronically ill or paranoid about becoming chronically ill. It is suggested that this obsession may have its own negative health effects, such as stress and depression (Brashers, 2001). In addition, individuals' who have had little prior experience, such as those aged 18 to 24 , with a health problem may lack the proper schema or interpretative framework needed to interpret situations related to an illness (Brashers et al., 1999). In effect, this may lead to difficulties communicating about an STI, especially among individuals who are lacking the necessary communication skills. Based on this reasoning, the following hypothesis was posited: 
H7: Among individuals who have had an STI, those who have self-disclosed about their STI will have higher communication competence scores than will those who have not self-disclosed about their STI.

\section{Communication Apprehension}

Communication apprehension, the anxiety one feels when communicating with another, has been found to have a negative impact on several communication variables. For example, Rubin and Rubin (1989) used McCroskey's Personal Report of Communication Apprehension-24 to explore the relationship between communication apprehension and communication satisfaction. Results from this study indicated that communication apprehension and satisfaction are negatively related. More specifically, participants reported that as apprehension in dyadic situations increased, the dissatisfaction with the communication increased when it involved friends. In another study involving communication apprehension, it was found that an individual's level of trait communication apprehension was a strong predictor of job choice (Daly \& McCroskey, 1975). Individuals who are apprehensive about communication prefer occupations that require little or no communication, whereas individuals lower in communication apprehension prefer jobs that allow for more communication. In addition, communication apprehension is a personality trait that has been associated with several health-related behaviors. For example, research has found that as communication apprehension decreased, female patients' willingness to talk about gynecological topics increased with their gynecologists (Wheeless, 1984). The results of this study also indicated that among the 156 female participants, communication apprehension was negatively related to patients' overall knowledge concerning gynecological health needs. It can be reasonably assumed that individuals that are unwilling to 
discuss basic gynecological needs will have trouble discussing the contraction of an STI. Based on this reasoning, the following hypothesis was posited:

H8: Among individuals who have had an STI, interpersonal communication apprehension and time between diagnosis and self-disclosure of an STI will be positively related.

\section{Time from Diagnosis to Disclosure}

Individuals who have contracted an STI may differ in both the psychological or physical effects. Therefore, the time it takes to disclose may vary greatly. If the need for emotional support is high, a person may be more or less inclined to disclose at different points in time. Time may also be highly correlated with different personality traits that may, or may not, have an effect on time between infection and disclosure. Agne et al. (2000) found that individuals suffering from HIV/AIDS chose to disclose about their condition to family members, friends, employers, and insurance agencies for different reasons. Still, some individuals chose to remain silent about their condition altogether.

RQ1: How much time does it take for an individual to self-disclose about acquiring an STI?

Comparison of the STI Sample to Non-STI Sample on Personality

Assessing different communication patterns between those who have and have not had an STI is important to further our knowledge base regarding possible differences between personality traits and communication behaviors.

RQ2: Are there personality differences between individuals who report having had an STI and those who have never had an STI? 
Certain aspects of the research, specifically interpersonal communication patterns, has been deficient of sound conclusions and/or research altogether. The present study intends to shed light on this serious health epidemic. 


\section{CHAPTER 2}

Method

\section{Participants}

Participants were 148 undergraduate (104 females, 46 males) students enrolled in communication classes at a large Mid-Atlantic university. Participation was voluntary, and extra credit was awarded to participants. The average age of the participants was 21 years old (31.1\% male, $68.9 \%$ femal). It should be noted that of the 1000 surveys originally distributed, 612 were completed and returned (362 females, 250 males). Of the 612 participants who completed and returned the survey, 74 answered yes to having had an STI (males $=23$, females $=51$ ). In order to have an equal number of participants in the comparison group, 74 surveys were systematically chosen to be included to represent the individuals who reported never having had an STI (i.e., surveys were separated by sex and randomly assorted, then every fifth survey was chosen from both sexes until the comparison group consisted of an a ratio of male/female participants that was equivalent to the STI group)

\section{Procedures and Instruments}

To maintain confidentiality, students were asked to take the questionnaires home to complete them in privacy. To further ensure privacy, each questionnaire was distributed in a 9x12 inch sealable envelope. Students were instructed not to leave identifying marks on either the questionnaire itself or the envelope. Upon completion, respondents placed their questionnaires into the provided envelopes, sealed the envelope, and placed them into a large, secured box located at the front of the classroom during classtime. The box was kept in a locked office after collection. There were sheets of paper beside the box for students to write down their personal code numbers for extra credit purposes. An announcement was made prior to the 
distribution of the surveys that all individuals under the age of 18 were not allowed to participate and were required to leave the room. Also, an announcement was made instructing students how to contact an on campus counseling center, if needed.

The questionnaire consisted of a cover page that explained the students' rights, where to go for psychological help or to obtain answers for any questions, and the Institutional Review Board's stamp of approval for the study (see appendix H). Following the cover page, there were five pages consisting of six measures, demographic information (e.g., sex, age,) and several author developed questions (see appendix A-G).

A one-item question was asked to indicate sex of the participants. The answer indicated (1) for female and (2) for male. A one-item question asked participants "Have you ever had a Sexually Transmitted Infection?" The answer format will be (1) for yes and (2) for no. A oneitem question asked "how long did you wait to tell someone about your Sexually Transmitted Infection?" The answers included immediately, within a week, within a month, within a year, have never told anyone, and not applicable. A one-item question asked respondents to identify the category of the person that they disclosed to first and second. The categories were (1) family member, (b) friend, (c) romantic partner, (d) internet source (i.e., chat room), (e) other, or (f) not applicable. A one-item question was asked to assess the participant's primary motivation for disclosing or for not disclosing to another about their STI. The statements read "I disclosed about my sexually transmitted infection to" and each of the following motivations were included to complete the statement: to relieve pent of feelings and emotions, to understand myself better, I thought the other person needed to know, I care about what others think about me, to strengthen my relationship with that person, and not applicable. 
Seven scales were used to assess interpersonal communication traits related to selfdisclosure. They were the (a) Communication Competence Scale (CSS: Wiemann, 1977), (b) the Interpersonal Trust Scale (ITS: Rotter, 1967), (c) the Revised Self-Disclosure Scale (RDSD: Wheeless \& Grotz, 1976), (d) the conscientiousness factor of the NEO Personality Inventory (NEO FFI: Costa \& McCrae, 1992), (e) the Health Locus of Control Scale (Wallston, Wallston, Kaplan, \& Maides, 1976), and (f) the Interpersonal anxiety portion of the Personal Report of Communication Apprehension-24 (PRCA-24: McCroskey, 1978).

The Communication Competence Scale is a 36-item scale. The scale is designed to assess how well individuals communicate with one another in a variety of contexts and situations. Respondents answered on a five-point Likert-type scale with responses ranging from strongly disagree (1) to strongly agree (5). Thus, higher scores are indicative of greater self perceptions of communication competence. Sample items include: "I find it easy to get along with others," "I do not mind meeting strangers," and "I am not afraid to speak with people in authority." One modification was made to the original scale. Instead of the observer report, a self report was made to reflect one's own perception of one's communication competence. Prior research has examined the relationship between communication competence and social support seeking behaviors. Results indicated that individuals who perceive themselves to be higher in communication competence reported more social networks and higher levels of social support satisfaction (Query, Parry, \& Flint, 1992). Previous studies have reported internal reliabilities of .90 (Query \& James, 1989). Using all 36 items, the internal reliability found for this scale in the current study was .92 .

The Interpersonal Trust Scale (ITS) is a 40-item scale measuring interpersonal trust, defined as the "generalized expectancy that the verbal statements of others can be relied upon" 
(Rotter, 1967, p. 664). Items are scored on a five-point Likert-type scale ranging from least appropriate (1) to most appropriate (5). Thus, higher scores are indicative of greater self perceptions of interpersonal trust. Sample items include: "Most people can be counted on to do what they say they will do," "In these competitive times one has to be alert or someone is likely to take advantage of you," and "Most people are honest in describing their products." Rotter $(1967 ; 1971 ; 1980)$ provided considerable data supporting the reliability and validity of the ITS in a variety of contexts, such as the impact that interpersonal trust has on the development of family relationships and of healthy personalities in children. More specifically, research has investigated how parents' trust levels correlate with the trust levels of their college aged children, indicating that fathers have a fairly large effect on their sons' level of trust, whereas the effect on their daughters' interpersonal trust is negligible. However, mothers were found to have a small and equal effect on both sons and daughters interpersonal trust (Katz \& Rotter, 1969). Prior research has indicated a .76 for internal reliability (Rotter, 1967). The internal reliability found for this scale within the present study was .85 .

The Revised Self-Disclosure Scale was used to measure the extent to which one individual communicates to another about herself/himself. It is a 31-item self-report instrument in which respondents answer on a five-point Likert-type scale with responses ranging from strongly disagree (1) to strongly agree (5). Higher scores indicate having a greater propensity to disclose. Sample items include: "When I express my personal feelings, I am always aware of what I am doing and saying," "I often talk about myself," and "I am not always honest in my self-disclosures." Five separate functions of self-disclosure are examined using the scale, including intended disclosure, amount, positive-negative, control of depth, and honesty-accuracy. Prior research has used this scale to examine several constructs, such as trust and interpersonal 
solidarity (Wheeless, 1978). The results of that study indicated that self-disclosure and perceived trustworthiness of the individual who was the target of the disclosure were found to be positively correlated. Also, self-disclosure and perceived trustworthiness of the individual were found to be attributes of interpersonal solidarity. Prior research has obtained internal reliabilities of the five constructs ranging from .68 to .83 and internal reliability for the entire construct of .91 (Rosenfeld, 1979). The internal reliability found for this scale used within the present this study was $.81, .82, .90, .79$, and .90 , respectively.

The NEO Five-Factor Inventory was used to assess personality. It is a short version of the Revised NEO Personality Inventory (NEO PI-R) based on the five-factor model of personality (Costa \& McCrae, 1992). Each of the five personality traits is measured by 12 items, for a total of 60 items. For this study, only the questions measuring trait conscientiousness were implemented. The items are statements measured by five-point Likert type scale with responses ranging from strongly disagree (1) to strongly agree (5). Higher scores are indicative of a greater self perception of personal conscientiousness. Sample items include: "I keep my belongings clean and neat," "I work hard to accomplish my goals," and "I never seem to be able to get organized." Past research has used the scale to investigate how conscientious individuals lead lives that may contribute to better health outcomes. For example, a longitudinal study of college educated women was conducted that examined levels of conscientiousness, social environmental factors, and health behaviors. The results indicated women who were reported higher levels of conscientiousness in college were more likely to have more children and experience lower rates of divorce, which leads to longevity, than women who reported being less conscientious (Roberts, Walton, \& Bogg, 2005). Prior studies have obtained an internal reliability of .81 for 
conscientiousness (Costa \& McCrae, 1992). The internal reliability found for the scale in the present study was .93 for the conscientiousness factor.

The Health Locus of Control Scale is an 11-item forced choice instrument designed to measure an individual's health locus of control. Health locus of control is the extent to which an individual believes that his/her health is under his/her own power. There are two ends of the locus of control continuum, external and internal. Individuals who have an external locus of control believe that their health is based on luck, whereas individuals with an internal locus of control believe that they have full control over their health. The items are statements measured by five-point Likert type scale with responses ranging from strongly disagree (1) to strongly agree (5). Higher scores are indicative of individuals who have an external health locus of control, whereas lower scores indicate individuals who have an internal health locus of control . Sample items include: "If I take care of myself, I can avoid illness," "Most people do not realize the extent to which their illnesses are controlled by external happenings," and "People who never get sick are just plain lucky." Research has used this scale to examine several constructs. More specifically, Tait, DeGood, and Carron (1982), used the scale to investigate the difference between health locus of control in patients suffering from lower back pain the United States and New Zealand. The results indicated that New Zealanders maintained more internal control over health, whereas Americans were more external. Also, women reported having less personal control over pain conditions than men across both countries. Prior studies have reported an internal reliability of .71 (Wallston et al., 1976). The internal reliability found for this scale in the present study was .75 .

The Personal Report of Communication Apprehension scale-24 is a 24-item scale used to measure an individual's level of anxiety associated with communicating with others 
(McCroskey, 1982). The items are statements respondents evaluate using a five-point Likert type scale with responses ranging from strongly disagree (1) to strongly agree (5). Thus, higher scores are indicative of individuals who are more anxious when communicating with others. One modification was made to this scale for this study. Only the interpersonal anxiety factor of the scale, consisting of six questions, was used. Sample items include: "While participating in a conversation with a new acquaintance, I feel very nervous," "I have no fear of speaking up in conversations," and "Ordinarily I am very tense and nervous in conversations." Previous research has used the scale to explore different communication scenarios, such as the professional lives of chiropractors, pharmacists, and students (McCroskey \& Beatty, 1984; McCroskey, Beatty, Kearney, \& Plax, 1985). Overall, results from the various studies have indicated that communication apprehension negatively affects an individual's interaction ability. More specifically, individuals with high communication apprehension have been consistently found to be less willing to communicate and tend to avoid and/or withdraw from communication with others more often than low communication apprehension individuals. Prior studies have reported an internal reliability of .94 (Chen, 1994). The internal reliability found for this scale used in the present study was 90 .

Data Analysis

To test the first, second, third, and fourth hypotheses, independent sample $t$-tests were used to determine the relationship between self-disclosure and level of conscientiousness, contraction of sexually transmitted infections and level of conscientiousness, self-disclosure and health locus of control, and health locus of control and contraction of sexually transmitted infection. In testing the first and third hypotheses, only the sample that had contracted an STI was examined. To test hypothesis five, a chi-square test was used to determine the relationship 
between self-disclosure and sex within the sample that had contracted a sexually transmitted infection. To test hypotheses six and seven, a $t$-test was used to determine the relationship between self-disclosure and interpersonal trust and the relationship between self-disclosure and communication competence. To test hypothesis eight, a Pearson correlation was used to assess the relationship between individuals' level of interpersonal communication apprehension and the time taken to disclose about an STI contraction. To answer the first research question, a frequency analysis was used to determine the relationship between time and self-disclosure. To answer the second research question, a t-test was used to determine the relationship between contraction of a sexually transmitted infection and personality. In addition, Pearson correlations and a partial correlation were used to assess several post hoc analyses, specifically, to determine relationships between personality traits, motives for disclosure, functions of self-disclosure, and time taken from diagnosis to disclosure. A frequency analysis was used to assess the most common motivation for self-disclosing and time from diagnosis of an STI to self-disclosure. 


\section{CHAPTER 3}

Results

\section{Descriptive Statistics}

The average age of the participants ( $\mathrm{n}=148,46$ males, 102 females) in the present study was 21 years old $(21.34, S D=4.00)$, with a minimum age of 18 and a maximum age of 55 . Seven scales were used to assess interpersonal communication traits related to self-disclosure about a sexually transmitted infection. All of the items, within the seven scales utilized in the present study, were included when analyzing the data. The scales reported the following means, standard deviations, and standardized alpha reliabilities (see Table 1): Communication Competence Scale $(M=142.00, S D=13.61, \alpha=.92)$, the Interpersonal Trust Scale $(M=36.00$, $\mathrm{S} D=6.09, \alpha=.85)$, the five dimensions of the Revised Self-Disclosure Scale (intent ( $M=$ 14.69, $S D=2.31, \alpha=.81)$, amount $(M=20.49, S D=4.07, \alpha=.82)$, positive-negative $(M=$ 24.80, $S D=4.26, \alpha=.90)$, control of depth $(M=12.78, S D=3.43, \alpha=.79)$, honesty-accuracy $(M=27.73, S D=5.15, \alpha=.90)$, total of all five dimensions of self-disclosure $(M=100.67, S D=$ $11.41, \alpha=.83))$, the conscientiousness factor of the NEO Personality Inventory $(M=43.45, S D$ $=7.87, \alpha=.93)$, the Health Locus of Control Scale $(M=30.03, S D=4.58, \alpha=.75)$, and the interpersonal anxiety factor of the Personal Report of Communication Apprehension-24 $(M=$ $14.15, S D=4.56, \alpha=.90)$. Note: Item means are reported for the remainder of the results section.

\section{Hypothesis One}

The first hypothesis stated that individuals who have had a sexually transmitted infection and are high in trait conscientiousness will be more likely to self-disclose to another (i.e., family member, friend, romantic partner, online source, other) about an STI than individuals who had 
contracted an STI and were low in trait conscientiousness. The analysis included only the participants who had reported having contracted an STI $(n=74)$. Results of an independent sample $t$-test did not support this hypothesis $(t(72)=-1.31 \cdot p=.192)$. The conscientiousness scores of participants who had never disclosed about their STI $(n=9, M=3.31, S D=.58)$ were not significantly different than those who had disclosed $(n=65, M=3.61, S D=.68)$ to others about an STI in self-reported levels of conscientiousness. Hypothesis one was not supported. Hypothesis Two

Hypothesis two predicted that individuals who had contracted a STI would be lower in trait conscientiousness than individuals who had never contracted an STI. The analysis involved comparing the participants who had reported having contracted an STI with the participants who reported never having contracted an STI on their levels of conscientiousness. Results of a $t$-test did not support the hypothesis $(t(146)=-.75, p=.454)$. The conscientiousness scores of participants who had reported having contracted an STI $(n=74, M=3.58, S D=.67)$ were not significantly different than those who reported not having contracted an STI ( $n=74, M=3.66$, $S D=.64)$ in levels of conscientiousness. Hypothesis two was not supported.

\section{Hypothesis Three}

The third hypothesis stated that individuals who have an external health locus of control would be less likely to self-disclose about their sexually transmitted infection than participants with an internal health locus of control. The analysis included only the participants who had reported having contracted an STI. Results of a $t$-test did not support this hypothesis $(t(72)=-.344 . p=.732)$. The external health locus of control scores of participants who had never disclosed about their STI $(n=9, M=2.75, S D=.37)$ were not significantly different than 
those who had disclosed to others about an STI $(n=65, M=2.80, S D=.44)$ on health locus of control. Hypothesis three was not supported.

\section{Hypothesis Four}

Hypothesis four predicted that individuals who reported having an external health locus of control will be more likely to acquire a STI than individuals who reported having an internal health locus of control. The analysis involved comparing the participants who had reported having contracted an STI with the participants who reported never having had an STI on health locus of control. Results of an independent sample $t$-test indicated support for the fourth hypothesis $(t(146)=1.86 . p=.06$ (one-tailed) $)$. The external health locus of control scores of participants who had contracted a sexually transmitted infection $(n=74, M=2.79, S D=.43)$ were higher than the scores of those participants who had never contracted an STI $(n=74, M=$ $2.67, S D=.40)$ on health locus of control. Individuals who had contracted an STI reported having less control over their health (i.e., external HLC). Hypothesis four was supported.

\section{Hypothesis Five}

The fifth hypothesis stated that women were more likely than men to self-disclose about their STI. The analysis included only the participants who had reported having contracted an STI. The results of a $2 \times 2$ (sex $\mathrm{X}$ disclosure) chi-square analysis indicated support for the hypothesis, $\left(x^{2}=6.06, p=.02\right)$, with more women $(94 \%)$ reporting having self-disclosed about their STI than men (74\%). From another analytical perspective, a $t$-test also supported that there was a significant difference $(t(27)=-2.08, p=.04)$ between women $(M=.74, S D=.44)$ and men $(M=.94, S D=.23)$ on self-disclosures about an STI. Hypothesis five was supported. 


\section{Hypothesis Six}

Hypothesis six forwarded that individuals who had self-disclosed to another (i.e., family

member, friend, romantic partner, online source, other) about their STI are more likely to be high in levels of interpersonal trust than individuals who reported not having disclosed about their STI. The analysis included only the participants who had reported having contracted an STI. Results of an independent sample t-test did not support this hypothesis $(t(72)=.63, p=.53)$. The interpersonal trust scores of participants who had never disclosed about their STI $(n=9, M=$ $2.50, S D=.21)$ were not significantly different than those who had disclosed $(n=65, M=2.41$, $S D=.42$ ) about their STI in interpersonal trust. Hypothesis six was not supported.

\section{Hypothesis Seven}

The seventh hypothesis stated that an individual high in communication competence will more readily self-disclose about their STI than an individual who is not as competent. The analysis included only the participants who had reported having contracted an STI. The results of an independent sample $t$-test did not support this hypothesis $(t(72)=-1.02, p=.311)$. The communication competence scores of individuals who self-disclosed about their STI $(n=65, M$ $=3.92, S D=.38)$ were not significantly different from the scores of individuals who did not selfdisclose $(n=9, M=3.78, S D=.35)$ on communication competence. Hypothesis seven was not supported.

\section{Hypothesis Eight}

The eighth hypothesis predicted that individuals higher in interpersonal communication apprehension would take longer to self-disclose about an STI than individuals lower in communication apprehension. The analysis included only the participants who had reported having contracted an STI. Results of a Pearson correlation indicated that interpersonal 
communication anxiety and time to self-disclose of the STI were positively related at a statistically significant level $(r=.29, p=.01)$. Hypothesis eight was supported.

\section{Research Question One}

The first research question asked how much time it takes for an individual that has acquired a STI to self-disclose about it. Results (table 6) of a frequency analysis indicated that most individuals tell others "immediately" $(n=42,56.8 \%)$, while "within 1 week" $(n=10$, $13.5 \%)$ and "never told anyone" $(n=9,12.2 \%)$ were the second and third most common answers regarding the time taken from diagnosis to disclosure. Other responses for the time that elapsed between when the individual was diagnosed with an STI and disclosure to another included "within 1 month" $(n=7,9.5 \%)$ and "within 1 year" $(n=5,6.8 \%)$. Thus, $70 \%$ disclosed about their STI diagnosis within the first week.

\section{Research Question Two}

The second research question asked if there were any personality differences between individuals who reported having had a STI and individuals who had reported never having contracted an STI. The analysis involved comparing the personality scores of participants who had reported having contracted an STI with the personality scores of the participants who reported never having had an STI. Only health locus of control was found to be significantly different between the two groups. Results of an independent sample t-test indicated that there is a significant difference $(t(146)=1.86 . p=.06$ (one-tailed) $)$ in health locus of control between participants who had contracted a sexually transmitted infection $(n=74, M=2.79, S D=.43)$ and those participants who had never contracted an STI $(n=74, M=2.67, S D=.40)$ on health locus of control. Yet, results of a t-test indicated no significant differences between individuals who reported having contracted a sexually transmitted infection and individuals who reported not ever 
having had an STI on the personality traits of conscientiousness $(t(146)=-751, p=.454)$, communication competence $((t(145)=-1.41, p=.16)$, interpersonal trust $(t(146)=.728, p=.47)$, communication anxiety $(t(143)=.142, p=.89)$, or self-disclosure $(t(142)=-1.02, p=.31)$.

Post Hoc Analyses

In addition to the aforementioned results, several post hoc analyses were performed to further explore the interrelationship of STIs, the self-disclosure process, and personality traits. A Pearson correlation was used to investigate the relationship between participants' various personality traits (i.e., conscientiousness, health locus of control, interpersonal trust, communication competence, and communication anxiety) and motivations for self-disclosing (i.e., relieve pent up feelings and emotions, understand myself better, thought the other person needed to know, care about what others think about me, and strengthen my relationship with that person) to others about their STI diagnosis. The results (table 2) indicated that conscientiousness, interpersonal trust, and communication anxiety were significantly correlated with several of the motives. More specifically, conscientiousness was negatively correlated with individuals selfdisclosing to "understand myself better" or because they "care about what others think of me." In contrast, trust was positively correlated with an individuals motive to self-disclose about an STI to "understand myself better" or because they "care about what others think of me." Both interpersonal trust and communication anxiety were negatively correlated with self-disclosing because the "other person needed to know."

Pearson correlations were used to determine the relationships between participants' motivations for self-disclosing about an STI diagnosis and the five dimensions of self-disclosure (i.e., intent, amount, positive-negative, control of depth, honesty-accuracy, and total of all five). The results (table 3 ) indicated that the motivation to "relieve pent up feelings and emotions" was 
negatively correlated with self-disclosure positivity-negativity, less control of depth, honestyaccuracy, and the total of all five dimensions of self-disclosure. The motivation "to understand myself better" was positively correlated with the disclosure less control depth. The motivation "care what others think of me" was positively correlated to less control of depth. The motivation of disclosing about an STI to "strengthen my relationship with that person" was also positively correlated with intent factor of self-disclosure.

Pearson correlations were also used to investigate the relationships among personality traits and the five dimensions of self-disclosure. The results (table 4) indicated that conscientiousness was significantly correlated to self-disclosure intent, positivity-negativity, honesty-accuracy, and the total of all five dimensions. Communication competence was found to be correlated to self-disclosure intent, positivity-negativity, and the total of all five dimensions. Communication anxiety was found to be negatively correlated with intent, positivity-negativity, honesty-accuracy, and the total of all five dimensions of self-disclosure.

Pearson correlations were used to determine the relationship between time from diagnosis with an STI until self-disclosure and motivations, personality traits, and self-disclosure. The results (table 5) indicated that time was negatively correlated with the motivation "the other person needed to know" and positively correlated with the motivation "I care about what others think of me." Time from diagnosis until disclosure was also negatively correlated with individuals' communication competence and conscientiousness but was positively correlated with interpersonal trust and communication anxiety. Time was negatively correlated with the intent factor of the self-disclosure. In addition, when controlling for the target of the selfdisclosure, partial correlations generally reinforced the results from the Pearson analysis, 
showing that the person who is the recipient of the disclosure does not affect the time of disclosure.

An independent sample $t$-test compared the interpersonal trust scores of the men in the STI sample $(M=2.57, S D=.39)$ with men in the non-STI sample $(M=2.31, S D=.45)$. The results indicated that men who had had an STI reported higher levels of interpersonal trust ( $t(44)$ $=2.13, p=.04)$. No significant difference was found for women's interpersonal trust and STI contraction. Also, a $t$-test was used to compare the STI sample $(M=2.57, S D=.39)$ with the non-STI sample $(M=2.31, S D=.45)$ on the dimensions of self-disclosure. Although none of the dimensions were significant, it should be noted that three dimensions of self-disclosure approached statistical significance, intent: $t(145)=-1.77, p=.078$, amount: $t(146)=1.67, p=$ .098 , and honesty-accuracy: $t(144)=-1.69, p=.093$.

A frequency analysis was used to determine the most common person that individuals self-disclose to about an STI contraction. The first person that the majority of individuals disclosed to was a romantic partner (37.8\%), and the second most common was a family member $(24.3 \%)$. Still others disclosed to a friend (12.2\%), online source $(5.4 \%)$, or other $(4.1 \%)$ first. The second person that most individuals tend to tell about an STI contraction is a friend (24.3\%), followed by a romantic partner $(21.6 \%)$, family member $(12.2 \%)$, other $(4.1 \%)$, or online source $(2.7 \%)$

In summary, the results showed that among a student population at a large university, STI's are prevalent and congruent with national statistics. Overall, the findings were mixed. The results from this study have revealed individuals' decision to self-disclose about an STI was related to individuals' level of interpersonal communication apprehension and sex. More specifically, participants with higher interpersonal communication apprehension take longer to 
disclose. Still, results found that more than $70 \%$ of individuals self-disclosed within the first week after diagnosis of an STI. Also, upon contraction of an STI, women were more likely to self-disclose than men, the first person most individuals tell about an STI diagnosis is either a romantic partner $(37.8 \%)$ or family member $(24.3 \%)$, and the most common motivation for selfdisclosing is because the other person needed to know. The results showed that $12 \%$ (14\% women, $10 \%$ men) of the students surveyed reported having had an STI. This number is consistent with the national statistic (13\%) for STI prevalence on a college campus. The personality traits of conscientiousness, health locus of control, interpersonal trust, or communication competence lacked sufficient support for the predictions made regarding selfdisclosure following an STI contraction. In addition, results indicated that individuals with an external health locus of control and men who reported higher levels of interpersonal trust were more likely to acquire an STI. However, within the entire sample $(n=148)$, having had an STI did not differ by conscientiousness, communication competence, communication anxiety, or selfdisclosure. Each of these findings will be discussed in more detail. 


\section{CHAPTER 4}

\section{Discussion}

\section{Implications}

The primary goal of this study was to determine the relationships between specific personality traits, contraction of a STI, and subsequent communication patterns. This study initially suggested a direct relationship between communication competence, interpersonal trust, self-disclosure, conscientiousness, health locus of control, interpersonal communication apprehension, and communication patterns following the acquisition of an STI. The findings from the current research further describe how individuals who have contracted an STI may communicate with others upon diagnosis. This research demonstrated that sex has an effect on the likelihood of one self-disclosing about an STI contraction. Also, the research demonstrated that conscientiousness, interpersonal trust, and communication anxiety are related to individuals' motivations for disclosing to others about an STI contraction. In addition, significant relationships were found between individuals' motivations for self-disclosure or seeking social support, personality traits, and the dimensions of self-disclosure. The relationship between individuals' personality traits and likelihood of contraction of an STI were also explored. More specifically, the research found that certain personality traits, such as conscientiousness, may not be an effective predictor of an STI contraction. However, an external health locus of control and men's interpersonal trust positively correlated with individuals' contraction of an STI. This study showed that time taken from diagnosis of an STI to self-disclosure about the STI is related to specific self-disclosure motivations, interpersonal trust, conscientiousness, communication anxiety, and the intent of self-disclosure. The research demonstrated that romantic partners are the most common target of disclosure of an STI diagnosis, followed by a family member. 
Analyses revealed that conscientiousness is negatively correlated with individuals' motivation to disclose for reasons of "to understand myself better" and "I care about what others think." This result suggests that as infected individuals' levels of conscientiousness increases, a desire to disclose to others for the self-disclosure function of clarity or face saving decreases. Conscientiousness was found to be related to the intent, positivity-negativity, and the total of all five dimensions of self-disclosure. Results also demonstrated a negative relationship between conscientiousness and the time from diagnosis to self-disclosure. Individuals with higher levels of conscientiousness, revealed a STI contraction more readily than individuals with lower levels of conscientiousness. This finding is in support of prior findings that state that conscientiousness is linked with a sense of duty and responsibility (Bogg \& Roberts, 2004).

No support was found for the prediction made in the first or second hypotheses that a relationship existed between individuals' level of conscientiousness and disclosure, or acquisition, of an STI. Prior research states that when making decisions about one's health, individuals who have higher levels of conscientiousness make more consistent and thorough decisions (Soane, 2005). Conscientiousness has been found to have an effect on behaviors related to risky sexual behaviors, as well as, illicit drug use and cardiovascular health (Contrada, Cather, and O'Leary, 1999). Support for the first hypothesis may have been lacking because this analysis included an unfavorable ratio between those who had and had not disclosed (nondisclosers $=9$, disclosers $=65)$. The second hypothesis's lack of support appears to indicate that an individual's level of conscientiousness is not an effective predictor of individuals' contraction of an STI. Among this age group, several other moderating variables may have affected this outcome. It could be suggested that the participants within the present study may have markedly higher levels of conscientiousness than the general public. This may be attributed to the sample 
population being in college and having more education. It could also be suggested that college students may let down their guard or "throw caution to the wind" when managing their heath. This behavior may be further exhibited through typical college activities, such as drinking alcohol, dorm-living, or living away from home for the first time, coupled with the fact that most college-aged students feel a sense of invincibility (Tyler et al., 2000). Also, only the students who completed and returned the surveys were analyzed. Completion of this task alone requires the students to have higher levels of conscientiousness.

The third and fourth hypotheses predicted that individuals with an external locus of control would be less likely to self-disclose about an STI contraction but more likely to acquire one. Individuals who have an external locus of control believe most things that occur in life happen by chance or luck or that their health is not something they necessarily have the power to control (Wallston \& Wallston, 1981). Support was found for the proposition that individuals who have an external locus of control are more likely to contract an STI. In the instance of contracting an STI, it makes sense that individuals who contract an STI are less likely to have practiced safer sex behaviors, such as wearing a condom. In fact, wearing condoms would be a practice exhibited by individuals who believe they have control over their health and demonstrate an internal health locus of control. No support was found for the prediction that individuals with an external health locus of control self-disclosed less. Though, an explanation for the lack of support may be that the analysis was restricted by the undesirable ratio ( 9 never disclosed, 65 had disclosed) of individuals within the STI group that could be used for this analysis. However, health locus of control was not found to have significant relationships with either motives for disclosure, the dimensions of self-disclosure, or time from diagnosis to disclosure. Thus, 
individuals who have an external locus of control may be at greater risk for contracting an STI, yet, the communication patterns following contraction (i.e., self-disclosure) may not be hindered.

The next set of analyses examined the relationship of sex and self-disclosure about an STI. Prior research has found that, overall, women self-disclose more often than men. The current study predicted, in line with earlier meta-analytical findings, that men would disclose less than women about health issues in particular (Dindia \& Allen, 1992). Society still expects a man to appear tough, achieving, unsentimental, and emotionally unexpressive (Dindia \& Allen, 1992). These attributes may lead men to self-disclose less often, especially following the contraction on an STI. The current study found that women were more likely to self-disclose about the contraction of an STI than men. Following diagnosis of an STI, women $(n=51)$ disclose nearly $95 \%$ of the time, in comparison, men $(n=23)$ were found to disclose only $74 \%$ of the time. Several explanations may be offered for this difference. First, it could simply be that women are self-disclosing more often about various topics than men, yet, there could be a deeper underlying explanation for this variance. It may be that women are more likely to become aware of an STI due to regular gynecology appointments, which routinely screen for STIs, whereas men may not be getting regular STI screenings and, as a result, are unaware of a possible infection. Therefore, men's lack of self-disclosure may be the direct result of a lack of awareness about an STI. Second, men may be less likely to complete a voluntary survey. For example, of the 1000 surveys originally distributed in this study, 612 were completed and returned, yet, women completed 100 more surveys than men (362 women, 250 men). It should be noted that there was a relatively equal ratio of men to women in each class that was used to collect data. Also, of those in the STI group, there was more than twice the number of women than men. In support of the present finding, research states that women are more likely to contract an STI due 
to physiology alone (Ericksen and Trocki, 1994). However, research does not indicate whether women contract STIs at twice the prevalence rate of men.

Interpersonal communication anxiety was found to inhibit an individual's decision to self-disclose. More specifically, the more anxious an individual was about communicating with others interpersonally, the more time it took an individual to disclose about an STI. This relationship is extremely consistent with prior research regarding communication anxiety. This finding suggests that if individuals, who are highly anxious about communication with others, contracts an STI, they may never tell the individuals with whom they are sexually active. Or the disclosure may be delayed. Both incidences may cause the spread of STIs.

Prior research has found that interpersonal trust affects a patients' willingness to seek care, reveal sensitive information, or receive treatment for an illness (Hall, Dugan, Zheng, \& Mishra, 2001). Sex and interpersonal trust seem inextricably linked. Thus, the current study predicted that individuals who reported higher levels of interpersonal trust would be more likely to self-disclose about an experience with an STI. But this was not supported. Post-hoc analyses examined the relationship between interpersonal trust and contraction of an STI. A significant relationship was found between men's interpersonal trust and contraction of an STI, in that, men who reported higher levels of interpersonal trust more likely to acquire an STI. These findings have several implications. If men, who are trusting, are more likely to contract an STI, there is a definite need to address an apparent lack of social responsibility within society. Further analyses found that trust does predict the time between diagnosis and self-disclosure but with counterintuitive results. As trust increased, time from diagnosis of an STI to self-disclosure increased. Previous findings involving interpersonal trust may suggest the opposite relationship between trust and time. Therefore, interpreting this finding is rather difficult. It may be suggested 
that the report of the participants' interpersonal trust was determined at the time of survey completion, whereas the time during which the infection took place was unknown. It could reasonably be argued that, although an individual is high in trust at survey completion, during the time following the actual infection, trust had been violated, and the individual was not as trusting. For example, if an infection occurred during high school, levels of interpersonal trust may have been lower. Also, it is possible that reporting higher levels of trust may have been linked to social desirability. More specifically, if an individual has had an STI, there may be a need within that individual to demonstrate control over emotions and not allow the STI to affect ones' view of the world negatively. Individuals may internalize their high levels of interpersonal trust and, therefore, trust in themselves that they can deal with the STI diagnosis on their own. Even seeking social support from a friend may not be likely, especially if the individual is concerned about the consequences of the disclosure should the friendship dissolve. Also, individuals may not disclose if they are afraid of losing others trust. These scenarios would eliminate any immediate desire to self-disclose and explain the results found within the study.

Analyses also revealed that interpersonal trust is correlated with specific motivations to self-disclose. A positive correlation was found between trust and several motives of the selfdisclosure about an STI contraction. Trust was positively correlated with the motives "I disclosed to understand myself better" and "I disclosed because I care what others think of me." The motive "I disclosed because I thought the other needed to know" was found to have a negative relationship with trust. This implies that as trust increases, individuals are less comfortable disclosing about their STI, yet, individuals will disclose to others who they believe need to know, regardless of trust. This finding is important because it demonstrates that individuals may 
disclose to the person who infected them, despite how damaged their trust may have been as a result of the possible contraction from that person.

From both a medical and communication perspective, the disclosure processes following an STI contraction are important. Prior research states that competent communicators are perceived as being motivated to communicate, knowledgeable about how to communicate, capable of utilizing their knowledge, sensitive to the communication content, and capable of achieving outcomes in their communication interactions (Spitzberg \& Cupach, 1984). Hence, individuals who reported higher levels of communication competence should be more likely to self-disclose about an STI. Yet, no support was found for this prediction. Reasons for the lack of support found may be a result of the overwhelming ratio of individuals who had disclosed about an STI compared to individuals who had not. Other analyses of personality traits, especially conscientiousness, health locus of control, interpersonal trust regarding self-disclosure within the STI sample were limited due to the ratio of nine non-disclosers to 65 disclosers. The nine individuals who chose to not disclose about an STI may be representative of a possible larger trend occurring among the STI population. These individuals, combined with those who are unaware of an infection, could be largely responsible for the spread of STIs. It is essential that more research penetrate into the minds of these individuals and attempts to gain a better perspective on why they choose not to tell anyone.

Results of a post-hoc analysis did support that communication competence was negatively correlated with time from diagnosis until disclosure, indicating that, individuals who were more competent self-disclosed sooner than lower competent communicators. Implications of this finding are favorable. It provides hope that teaching individuals how to be better and more effective communicators may increase the quality of their life by minimizing negative health 
issues. If an individual becomes a more competent communicator and, as a result, is more likely to seek social support for an STI, the potential for positive outcomes is great. For example, research states that social support promotes better health and psychological well-being (Shaw et al., 2004). Further analyses also revealed that communication competence was related to an individuals' intent of disclosure, positivity-negativity, and the total of all five dimensions of selfdisclosure. Upon disclosing about an STI, individuals who are more skilled communicators, report disclosing for a specific purpose, display more positive disclosures, and feel more comfortable disclosing overall.

The time it takes for an individual who is diagnosed with an STI to self-disclose to another (i.e., family member, friend, romantic partner, online source, other) may be crucial both in social support seeking and preventing the spread of STIs. More than $70 \%$ of the sample with an STI reported disclosing to another within the first week. The majority of participants told someone immediately (57.5\%), while the second most common disclosure time was "within 1 week" (13.7\%) from diagnosis. It should be cautiously celebrated because the third most common answer was "never told anyone" (12.3\%).

Implications of the results are mixed. The fact that more than $70 \%$ of infected individuals will self-disclose within the first week gives health practitioners and educators a time frame on which to focus their efforts and attention. But if individuals do not disclose within the first week, the results suggest that they may never disclose. This is concerning but somewhat consistent with prior research. Keller et al. (2000) investigated self-disclosure of HPV to sexual partners and found that although participants would disclose to sexual partners at the time of diagnosis, they would not disclose to new partners six months later. Interestingly, $30 \%$ of the participants in Keller et al's study were either unsure or did not believe that they had a responsibility to tell their 
casual sexual partners about their HPV. Unfortunately, it is this attitude and behavior that may increase the spread of STIs.

The second research question asked whether personality differences existed between individuals that had contracted an STI and those who had not. The results were mixed. Initial analysis revealed that health locus of control and men's interpersonal trust alone showed significant differences between those that had and had not contracted an STI. The implications of these findings were discussed prior. No other personality differences were found to be linked to the acquisition of an STI. Still, results of a post-hoc analysis indicated that within the overall self-disclosure measure, intent, amount, and honesty-accuracy approached statistical significance. The lack of support linking personality traits to STI contraction and subsequent communication patterns could be due to the population or the specific traits used within this study. Despite the wide variety of individuals attending any university, college students tend to be more alike than different. It could be these similarities that constrict the evidence linking personality traits and STI contraction and communication patterns.

Several post hoc analyses offered researchers a clearer view of the communication patterns following the acquisition of an STI. Specifically, motivations for self-disclosure were analyzed. Individuals reported that the most common reason for self-disclosing was because they believed the other person needed to know. This finding has potentially enormous implications for society. It provides insight on how health advocates should reinforce the important health benefits of telling the people who have a right and need to know, such as romantic/intimate partners, who are at the greatest risk of transmission. These results indicate that nearly $38 \%$ of individuals do feel a sense of responsibility about notifying their current romantic partners first. 
Post-hoc analyses revealed that the first person that infected individuals tell is their romantic partner. Implications of this finding may indicate a step in the right direction for health advocates and healthcare. The notion that after gaining an awareness of an STI, most individuals tell their romantic partner, is what health advocates may like to hear. The spread of STIs will never diminish unless infected individuals practice social responsibility. This involves notifying the individual, upon contraction, that may have been responsible for the infection or the person who would be the most likely candidate to contract the STI from the infected individual. It does less good, as far as society is concerned, to only disclose about an STI to a friend or family member. Although discussion with a friend may be beneficial for the infected individual, ultimately, the romantic partner should be the first person to receive information.

\section{Limitations and Future Research}

This study has several limitations. The most obvious of these limitations deals with the size of the final sample. It has been found that nearly one-half of all sexually active individuals will contract a sexually transmitted infection by the time they turn 25 (The Henry J. Kaiser Family Foundation, 2003). Yet, within a college population, the infection rates are traditionally lower. Several national studies estimate that only about $13 \%$ of college students are infected with a sexually transmitted infection, (Kotloff et al., 1991), a rate that is very similar to this study's finding (12\%). Therefore, the current study, in an attempt to reach the general population of college students, had to pursue a large number of students in order to gain the 74 participants who reported having had an STI. A larger data set would have had more power to test the hypotheses. In addition, investigating a student-aged population not attending a university or from an alternative demographic, may prove to be productive. 
A second limitation of the research is the low number of male participants in comparison to females. The number of female participants $(n=104)$ was more than double the number of male participants $(n=46)$. However, this lack of male participation may be considered from another perspective. It provided support for the notion that females self-disclose more than males about an STI. The lack of male participation may have inhibited several of the analyses, specifically when examining personality traits of men in relation to STI contraction and subsequent self-disclosure patterns. Future research should strive to gather an equal number of male and female participants. This could enhance the possibility of a more accurate assessment of male versus female self-disclosure patterns following the acquisition of a sexually transmitted infection.

Finally, the study was limited by the lack of probing questions regarding STIs solicited within the questionnaire distributed to participants. While the questionnaire appropriately assessed whether the respondents had contracted an STI, it did not evaluate other important aspects of that contraction. For example, the questionnaire may have assessed sexual orientation or the type of STI contracted. Both of these variables may have played an important role in communication patterns before and following contraction. For example, Ericksen and Trocki (1994) found that sexual orientation was reported as the most important risk factor for men, with $34 \%$ of gays and bisexuals and $9 \%$ of heterosexuals having had at least one STI. Also, it has been suggested that gay men have multiple partnerships and may engage more frequently in sexual activity.

In light of the limitations and results of his study, future research should focus more readily on obtaining larger and differing types of samples (i.e., demographics), larger percentages of men, and examining varying effect of the personality on communication patterns, 
such as sensation seeking or religiosity. It may be important to assess how different types of STIs (viral versus non-viral) affect communication outcomes. In addition, conducting a longitudinal study to assess the relationship between the benefits, specifically for health and psychological well-being, of self-disclosing in the short-term versus long-term, may be worthwhile. This may be especially noteworthy due to the fact that this study found that most individuals either disclose immediately following a diagnosis or never disclose.

\section{Conclusion}

In the present study, the hypotheses and research questions addressed topics involving sexually transmitted infections and personality/communication variables that may affect an individual's decision to self-disclose or seek social support. For the most part, the personality and communication traits investigated within this study, as they relate to STIs, have been largely unexplored. Until recently, the bulk of STI research focused heavily on HIV/AIDS, due to the fact that HIV/AIDS did not become an important public issue until the 1980's. Also, despite the attention given to HIV/AIDS, other STIs have still remained largely in the background. This is especially true for issues regarding communication patterns and, more specifically, selfdisclosure. The current study helped answer several important questions regarding STIs, communication patterns, and personality traits. The results of this research will hopefully provide a foundation for future research on similar topic areas.

The decision to address the relationship between communication patterns following the acquisition of an STI, especially in relation to self-disclosure, was three-fold. First, exploring the possible effects of seeking or not seeking social support, for those individuals infected with an STI, involves a deep psychological element of communication that many times may be overlooked. Filling in the gaps in knowledge regarding this issue seems imperative to the 
advancement of both health research and humanity. Second, from a health advocacy standpoint, beginning to understand the logistics of why, when, and with whom, infected individuals disclose, is important for researchers to understand for the sake of the overarching society. Understanding these patterns may be the key to preventing and/or slowing the spread of this epidemic. For example, this research clarified several topics of importance. Specifically, individuals with an external health locus of control and higher interpersonal trust are more likely to acquire an STI, upon contraction women are more likely to self-disclose than men, individuals with high interpersonal communication apprehension take more time to disclose and more than $70 \%$ of individuals will self-disclose within the first week following diagnosis of an STI. In addition, the first person most individuals tell about an STI diagnosis is either a romantic partner or a family member, and the most common motivation for self-disclosing is because the other person needed to know.

Finally, to begin to understand why some individuals may be at a greater risk for contracting an STI due to personality traits seems like a logical foundation for research to build its future knowledge upon. Yet, lack of support for personality traits in relation to STIs may lead researchers to investigate STIs from a situational perspective versus the trait approach used within this study. Yet, overall, the research clarified several important issues regarding communication patterns following the acquisition of an STI. 


\section{References}

Agne, R. R., Thompson, T. L., \& Cusella, L. P. (2000). Stigma in the line of face: Self-disclosure of patients' HIV status to health care providers. Journal of Applied Communication Research, 28, 235-261.

Barth, K. R., Cook, R. L., Downs, J. S., Switzer G. E., \& Fischhoff, B. (2002). Social stigma and negative consequences: Factors that influence college students' decisions to seek testing for sexually transmitted infections. Journal of American College Health, 50, 153-160.

Bogg, T., \& Roberts, B. W. (2004). Conscientiousness and health-related behaviors: A meta-analysis of the leading behaviors. Psychological Bulletin, 130, 887-919.

Boney-McCoy, S., Gibbons, F. X., \& Gerrard, M. (1999). Self-esteem, compensatory selfenhancement, and the consideration of health risk. Personality \& Social Psychology Bulletin, 25, 954-965.

Booth-Butterfield, M. (2002). Interpersonal essentials. Boston: Allyn and Bacon.

Brackbill, R. M., Sternberg, M. R., \& Fishbein, M. (1999). Where do people go for treatment of sexually transmitted diseases? Family Planning Perspectives, 31, 10-17.

Bradner, C. H., Lu, L., \& Lindberg, L. D. (2000). Older, but not wiser: How men get information about AIDS and sexually transmitted diseases after high school. Family Planning Perspectives, 32, 33-38.

Brashers, D. E. (2001). Communication and uncertainty management. Journal of Communication, 51, 477-498.

Brashers, D. E., Neideg, J. L., Cardillo, L. W., Dobbs, L. K., Russell, J. A., \& Haas, S. M. (1999). 'In an important way, I did die': Uncertainty and revival in persons living with HIV or AIDS. AIDS Care, 11, 201-220. 
Brothers, D. (1995). Falling backwards ( $1^{\text {st }}$ ed.). New York: W.W. Norton \& Company.

Burleson, B. R. (2002). Introduction to the special issue: Psychological mediators of sex differences in emotional support. Communication Reports, 15, 71-80.

Carballo-Dieguez, A. (2001). HIV, barebacking, and gay men's sexuality. Journal of Sex Education \& Therapy, 26, 225-234.

Carrera, M., Kaye, J. M., Philliber, S., \& West, E. (2000). Knowledge about reproduction, contraception, and sexually transmitted infections among young adolescents in American cities. Social Policy, 30, 41-50.

Chen, G. M. (1994). Social desirability as a predictor of argumentativeness and communication apprehension. Journal of Psychology, 128, $72-79$.

Chesson, H. W., Blandford, J. M., Gift, T. L., Tao, G., \& Irwin, K. L. (2004). The estimated direct medical cost of sexually transmitted diseases among American youth, 2000. Perspectives on Sexual and Reproductive Health, 36, 11-19.

Christensen, A., Ehlers, S., Wiebe, J., Moran, P., Raichle, K., Ferneyhough, K., \& Lawton, W. (2002). Patient personality and mortality: A 4-year prospective examination of chronic renal insufficiency. Health Psychology, 21, 315-320.

Cleavenger, R. L., \& Juckett, G. (1996). Trends in chlamydia and other sexually transmitted diseases in a university health service. Journal of American College Health, 44, 263-267.

Cohen, D. A., \& Nsumani, M. (1999). Repeated school-based screening for sexually transmitted diseases: A feasible strategy for reaching adolescent. Pediatrics, 104, 1281-1287.

Contrada, R. J., Cather, C., \& O'Leary, A. (1999). Personality and health: Dispositions and 
processes in disease susceptibility and adaptation to illness. In L. A. Pervin \& O. P. John (Eds.), Handbook of personality: Theory and research (2nd ed., pp. 576-604). New York: Guilford Press.

Costa, P.T., \& McCrae, R.R. (1992). NEO PI-R. Professional manual. Odessa, FL: Psychological Assessment Resources.

Corbin, W. R., \& Fromme, K. (2002). Alcohol use and serial monogamy as risks for sexually transmitted diseases in young adults. Health Psychology, 21, 229-236.

Crosby, R. A., Sanders, S. A., Yarber, W. L., Graham, C. A., \& Dodge, B. (2002). Condom use errors and problems among college men. Sexually Transmitted Diseases, 29, 552-558

Daly, J. A., \& McCroskey, J. C. (1975). Occupational desirability and choice as a function of communication apprehension. Journal of Counseling Psychology, 22, 309-313.

Department of Health and Human Services. (2003). Male latex condom and sexually transmitted diseases. Center for Disease Control and Prevention. National Center for HIV, STD, and TB Prevention.

Dibble, S. L., \& Swanson, J. M. (2000). Gender differences for the predictors of depression in young adults with genital herpes. Public Health Nursing, 17, 187-194.

DiFranceisco, W., Ostrow, D. G., Adib, S. M., Chmiel, J. S., \& Hoffman, R. G. (1999). Predictors of long-term maintenance of safer sex and lapse/relapse: A nine-year followup of the Chicago CCS/MACS cohort. AIDS \& Behavior, 3, 325-334.

Dindia, K., \& Allen, M. (1992). Sex differences in self-disclosure: A meta-analysis. Psychological Bulletin, 112, 106-124.

Duran, R. L., \& Spitzberg, B. H. (1995). Toward the development and validation of a measure of cognitive communication competence. Communication Quarterly, 43, 
259-286.

Ericksen, K. P., \& Trocki, K. F. (1994). Sex, alcohol, and sexually transmitted diseases: A national survey. Family Planning Perspectives, 26, 257-269.

Flaherty, J., \& Richman, J. A. (1989). Gender differences in the perception and utilization of social support: Theoretical perspectives and an empirical test. Social Science and Medicine, 28, 1221-1228.

Fortenberry, D. J. (1997). Health care seeking behaviors related to sexually transmitted diseases among adolescents. American Journal of Public Health, 87, 417-423.

Friedman, H. S., Tucker, J. S., Schwartz, J. E., Martin, L. R., Tomlinson-Keasey, C., Wingard, D. L., \& Criqui, M. H. (1995). Childhood conscientiousness and longevity: Health behaviors and cause of death. Journal of Personality and Social Psychology, 68, 696-703.

Gerbase, A., Noriega-Minichiello, S., \& Vuylsteke, B. (1998). Sexually transmitted diseasesthe challenge. World Health, 51, 10-13.

Gillmore, M. R., Stielstra, S., Huang, B., Baker, S. A., Beadnell, B., \& Morrison, D. M. (2003). Heterosexually active men's beliefs about methods for preventing sexually transmitted diseases. Perspectives on Sexual and Reproductive Health, 35, 121-129.

Green, J. (2002). Psychological factors in sexually transmitted diseases. In D. Miller \& J. Green (Eds.), Psychology of sexual health (pp. 21-37). Oxford, England: Blackwell Science.

Goffman, E. (1963). Stigma: Notes on the Management of Spoiled Identity. Englewood Cliffs, NJ: Prentice Hall.

Gudykunst, W. B. (1995). Anxiety/uncertainty management (AUM) theory: Current status. In R. Wiseman (Ed.), Intercultural communication theory (pp. 8-58). Thousand Oaks, CA: Sage. 
Hall, M. A., Dugan, E., Zheng, B., \& Mishra, A. (2001). Trust in physicians and medical institutions: What is it, can it be measured, and does it matter? Milbank Quarterly, 79, 613-39.

Henry J. Kaiser Family Foundation. (1997). National survey of adolescents and young adults: Sexual health knowledge, attitudes, and experiences (pp. 1-76).

Henry J. Kaiser Family Foundation. (2000). National survey of adolescents and young adults: Sexual health knowledge, attitudes, and experiences (pp. 1-84).

Henry J. Kaiser Family Foundation. (2001). National survey of adolescents and young adults: Sexual health knowledge, attitudes, and experiences (pp. 1-137).

Henry J. Kaiser Family Foundation. (2003). National survey of adolescents and young adults: Sexual health knowledge, attitudes, and experiences (pp. 1-2).

Herek, G. M. (1997). The HIV epidemic and public attitudes towards lesbians and gay men. In M. P. Levine, P. Nardi, \& J. Gagnon (Eds.), In changing times: Gay men and lesbians encounter HIV/AIDS (pp. 191-218). Chicago: University of Chicago Press.

Herek, G. M., Capitiano, C. P., \& Widaman, K. F. (2003). Stigma, social risk, and health policy: Public attitudes toward HIV surveillance policies and the social construction of illness. Health Psychology, 22, 533-540.

Hill, C. T. (1991). Seeking emotional support: The influence of affiliative need and partner warmth. Journal of Personality and Social Psychology, 60, 112-121.

Hogan, J., \& Ones, D. S. (1997). Conscientiousness and integrity at work. Handbook of Personality \& Psychology (pp. 849-870). San Diego: Academic Press.

Horner, K. L. (1996). Locus of control, neuroticism, and stressors: Combined influences on reported physical illness. Personality and Individual Differences, 21, 195-204. 
Jonzon, E., \& Lindblad, F. (2005). Adult female victims of child sexual abuse. Journal of Interpersonal Violence, 20, 651-667.

Katz, B. P., Fortenberry, J. D., Zimet, G. D., Blythe, M. J., \& Orr, D.P. (2000). Partner-specific relationship characteristics and condom use among young people with sexually transmitted diseases. Journal of Sex Research, 31, 69-77.

Katz, H. A., \& Rotter, J. B. (1969). Interpersonal trust scores of college students and their parents. Child Development, 40, 657-662.

Keller, M. L., Sadovszky, V. V., Pankratz, B., \& Hermsen, J. (2000). Self-disclosure of HPV infection to sexual partners. Western Journal of Nursing, 22, 285-302.

Kelley, S. S., Borawski, E. A., Flocke, S. A., \& Keen, K. J. (2003). The role of sequential and concurrent sexual relationships in the risk of sexually transmitted diseases among adolescents. Journal of Adolescent Health, 32, 296-305.

Knoll, N., Rieckmann, N., Scholz, U., \& Schwarzer, R. (2004). Predictors of subjective age before and after cataract surgery: Conscientiousness makes a difference. Psychology and Aging, 19, 676-688.

Kotloff, K. L., Tackett, C. O., Wasserman, S. S., Bridwell, M. W., Cowan, J. E., \& Clemens, J. D. (1991). A voluntary serosurvey and behavioral risk assessment for human immunodeficiency virus infection among college students. Sexually Transmitted Diseases, 18, 223-227.

Lau, R. R. (1982). Origins of health locus of control beliefs. Journal of Personality \& Social Psychology, 42, 322-334.

Lederman, R. P., \& Mian, T. S. (2003). The parent-adolescent relationship education (pare) program: A curriculum for prevention of STDs and pregnancy in middle school youth. 
Behavioral Medicine, 29, 33-41.

Maher, J. E., Peterman, T. A., Osewe, P. L., Odusanya, S., \& Scerba, J. R. (2003). Evaluation of a community-based organization's intervention to reduce the incidence of sexually transmitted diseases: A randomized, controlled trial. Southern Medical Journal, 96, 248-259.

Manne. S., Ostroff, J., Rini, C., Fox, K., Goldstein, L., \& Grana, G. (2004). The interpersonal process model of intimacy: The role of self-disclosure, partner disclosure, and partner responsiveness in interactions between breast cancer patients and their partners. Journal of Family Psychology, 18, 589-599.

Mcauslan, P. (1999). After sexual assault: The relationship between women's disclosure, the reactions of others, and health. Dissertation Abstracts International: Section B: The Sciences \& Engineering, 60 (1-B), 411.

McCroskey, J. C. (1978). Validity of the PRCA as an index of oral communication apprehension. Communication Monographs, 45, 192-203.

McCroskey, J. C. (1982). An introduction to rhetorical communication. Englewood Cliffs, NJ: Prentice-Hall.

McCroskey, J. C., \& Beatty, M. J. (1984). Communication apprehension and accumulated communication state anxiety experiences: A research note. Communication Monographs, $51,79-84$.

McCroskey, J. C., Beatty, M. J., Kearney, P., \& Plax, T. G. (1985). The content validity of the PRCA-24 as a measure of communication apprehension across communication contexts. Communication Quarterly, 33, 165-173. 
Moffett, L. A., Steinberg, S. L., \& Rohde, P. (1996). Personality assessment of substancedependent patients in a therapeutic community. Journal of Substance Abuse Treatment, $13,127-134$.

Murphey, P. A., \& Nagy, S. (2002). Group membership and STI knowledge among adolescents. American Journal of Health Studies, 17, 203-208.

Ong, A. D., \& Weiss, D. J. (2000). The impact of anonymity on responses to sensitive questions. Journal of Applied Social Psychology, 30, 1691-1708.

Parks, M. R. (1994). Communicative competence and interpersonal control. In M. L. Knapp \& G. R. Miller (Eds.), Handbook of interpersonal communication ( $2^{\text {nd }}$ ed., pp. 589-618). Thousand Oaks, CA: Sage.

Pearlin, L. I., \& McCall, M. E. (1990). Occupational stress and marital support: A description of microprocesses. Stress between work and family (pp. 39-60). New York: Plenum Press.

Portner, J. (1996). Effort to wipe out sexually transmitted diseases targets adolescents. Education Week, 16, 7-9.

Pluhar, E. I., Frongillo, E. A., Stycos, J. M., \& Dempster-McClain, D. (2003). Changes over time in college students' planning knowledge, preference, and behavior and implications for contraceptive education and prevention of sexually transmitted infections. College Student Journal, 37, 420-434.

Query, J. L., \& James, A. C. (1989). The relationship between interpersonal communication competence and social support groups in retirement communities. Health Communication, 1, 165-185.

Query, J. L., Parry, D., \& Flint, L. J. (1992). The relationship among social support, communication competence, and cognitive depression for nontraditional students. 
Journal of Applied Communication Research, 20, 78-95.

Richert, C. A., Peterman, T. A., Zaidi, A. A., Ransom, R. L., Wroten, J. E., \& Witte, J. J. (1993). A method for identifying persons at high risk for sexually transmitted infections: Opportunity for targeting infection. American Journal of Public Health, 83, 520-524.

Roberts, B. W., Walton, K. E., \& Bogg, T. (2005). Conscientiousness and health across the life course. Review of General Psychology, 9, 156-168.

Rosenfeld, L. B. (1979). Self-disclosure avoidance: Why am I afraid to tell you who I am? Communication Monographs, 46, 63-75.

Rosenthal, S. L., \& Biro, F. M. (1995). Strategies for coping with sexually transmitted diseases by adolescent females. Adolescence, 30, 655-666.

Rotter, J. B. (1967). A new scale for the measurement of interpersonal trust. Journal of Personality, 35, 651-665.

Rotter, J. B. (1971). Generalized expectancies for interpersonal trust. American Psychologist, 26, 443-452.

Rotter, J. B. (1980). Interpersonal trust, trustworthiness, and gullibility. American Psychologist, $35,1-7$.

Routbort, J. C. (1998). What happens when you tell: Disclosure, attributes, and recovery from sexual assault. Dissertation Abstracts International: Section B: The Sciences \& Engineering, 58 (10B), 5655.

Rubin, R. B., \& Rubin, A. M (1989). Communication apprehension and satisfaction in interpersonal relationships. Communication Research Reports, 6, 13-20.

Rudd, M. D. (2003). Warning signs for suicide. Suicide \& Life-Threatening Behavior, 33, 99100. 
Sadowski, C., \& Cognburn, H. (1997). Need for cognition in the big-five factor structure. The Journal of Psychology, 13, 307-312.

Shaffer, D. R., \& Ogden, J. K. (1986). On sex differences in self-disclosure during the acquaintance process: The role of anticipated interaction. Journal of Personality and Social Psychology, 51, 92-101.

Shaw, B. A., Krause, N., Chatters, L. M., Connell, C. M., \& Ingersoll-Dayton, B. (2004). Emotional support from parents early in life, aging, and health. Psychology and Aging, 19, 4-12.

Shumaker, S. A., \& Brownell, A, (1984). Toward a theory of social support: Closing conceptual gaps. Journal of Social Issues, 40, 11-36

Siegel, J. M., Sorenson, S. B., Golding, J. M., Burnan, M. A., \& Stein, J. A. (1989). Resistance to sexual assault: Who resists and what happens? American Journal of Public Health, 79, 27-32.

Simoni, J. M., Mason, H. R. C., Marks, G., Ruiz, M. S., Reed, D., \& Richardson, J. L. (1995). Women's self-disclosure of HIV infection: Rates, reasons, and reactions. Journal of Consulting, and Clinical Psychology, 63, 474-478.

Soane, E., \& Chmiel, N. (2005). Are risk preferences consistent? The influence of decision domain and personality. Personality \& Individual Differences, 38, 1781-1791.

Spitzberg, B. H., \& Cupach, W. R. (1984). Interpersonal communication competence. Beverly Hills: Sage.

Sprecher, S., \& Hendrick, S. S. (2004). Self-disclosure in intimate relationships: Associations with individual and relationship characteristics over time. Journal of Social and Clinical Psychology, 23, 857-877. 
Stanton, M., Leukefeld, L., Logan, T. K., Zimmerman, R.. Lynam, D., Mffich, R., Martin, C., McClanahan, K., \& Clayton, R. (1999). Risky sex behavior and substance use among young adults. Health \& Social Work, 24, 147-154.

Stokes, J. P. (1987). The relation of loneliness and self-disclosure. In V. J. Derlega \& J. H. Berg (Eds.), Self-disclosure: Theory, research, and therapy (pp. 175-201). New York: Plenum Press.

Tait, R., DeGood, D., \& Carron, H. (1982). A comparison of health locus of control beliefs in low-back patients from the U.S. and New Zealand. Pain, 14, 53-61.

Todd, C. S., Haase, C., \& Stoner, B. P. (2001). Emergency department screening for asymptomatic sexually transmitted infections. American Journal of Public Health, 91, 461-466.

Tyler, K. A., Whitbeck, L. B., Hoyt, D. R., \& Yoder, K. A. (2000). Predictors of self-reported sexually transmitted diseases among homeless and runaway adolescents. Journal of Sex Research, 37, 369-378.

Uchino, B., Cacioppo, J. T., \& Kiecolt-Glaser, J. K. (1996). The relationship between social support and psychological processes: A review with emphasis on underlying mechanisms and implications for health. Psychological Bulletin, 119, 488-531.

Umberson, D. (1987). Family status and health behaviors: Social control as a dimension of social integration. Journal of Health \& Social Behavior, 28, 306-319.

Valois, R. F., Oeltmann, J. E., Waller, J., \& Hussey, J. R. (1999). Relationship between number of sexual intercourse partners and selected health risk behaviors among public high school adolescents. Journal of Adolescent Health, 25, 328-335.

Vogel, D. L., \& Wester, S. R. (2003). To seek help or not seek help: The risks of self-disclosure. 
Journal of Counseling Psychology, 50, 351-361.

Wallston, K. A., \& Wallston, B. S. (1981). Health locus of control scales. In H. M. Lefcourt (Ed.), Research with the locus of control construct: Vol. 1. Assessment methods. New York: Academic Press.

Wallston, B.S., Wallston, K.A., Kaplan, G.D. \& Maides, S.A. (1976). Development and validation of the health locus of control (HLC) scale. Journal of the Consulting Clinical Psychologist, 44, 580-585.

Walsh-Childers, K. (1997). Sexual health coverage: Women's, men's, teen and other...Columbia Journalism Review, 36, 1-12.

Watson, D., \& Pennebaker, J. W. (1989). Health complaints, stress, and distress: Exploring the central role of negative affectivity. Psychological Review, 96, 234-254.

Weinstock, H., Berman, S., \& Cates, W., Jr. (2004). Sexually transmitted diseases among American youth: Incidence and prevalence estimates, 2000. Perspectives on Sexual and Reproductive Health, 36, 6-10.

West, R., \& Turner, L. H. (2003). Introducing communication theory: Analysis and application ( $2^{\text {nd }}$ ed.). Boston: Mayview.

Wheeless, L. R. (1978). A follow-up study of the relationships among trust, disclosure, and interpersonal solidarity. Human Communication Research, 4, 143-157.

Wheeless, V. E. (1984). Communication apprehension and trust as predictors of willingness to discuss gynecological health topics. Communication Research Reports, 1, 117-121.

Wheeless, L. R., \& Grotz, J. (1976). Conceptualization and measurement of reported selfdisclosure. Human Communication Research, 2, 338-346.

Whitten, K. L., Rein, M. F., Land, D. J., Reppucci, N. D., \& Turkheimer, E. (2003). The 
emotional experience of intercourse and sexually transmitted diseases: A decision-tree analysis. Sexually Transmitted Diseases, 30, 348-363.

Wiemann, J. M. (1977). Explication and test of a model of communication competence. Human Communication Research, 3, 195-214.

Wilson, S. N. (2000). Sexuality education: Our current status, and an agenda for 2010. Family Planning Perspectives, 32, 252-257.

Wright, T. L., \& Tedeschi, R. G. (1975). Factor analysis of the interpersonal trust scale. Journal of Consulting and Clinical Psychology, 43, 470-477.

Zaromatidis, K., Carlo, R., \& Racanella, D. (2004). Sex, perceptions of attractiveness, and sensation seeking and ratings of likelihood of having sexually transmitted diseases. Psychological Reports, 94, 633-636. 
Table 1

Descriptive Statistics of Variables Under Study

\begin{tabular}{lccc} 
Variable & Mean & $\underline{\text { SD }}$ & $\underline{\alpha}$ \\
\hline Communication Competence & 142.00 & 13.61 & .75 \\
Health Locus of Control & 30.03 & 4.58 & .85 \\
Interpersonal Trust & 36.00 & 6.08 & .93 \\
Conscientiousness & 43.45 & 7.87 & .90 \\
Communication Anxiety & 14.15 & 4.56 & .81 \\
Self-disclosure Intent & 14.69 & 2.31 & .82 \\
Self-disclosure Amount & 20.49 & 4.07 & .90 \\
Self-disclosure Positive-Negative & 24.80 & 4.26 & .79 \\
Self-disclosure Control & 12.78 & 3.43 & .90 \\
Self-disclosure Honesty-Accuracy & 27.73 & 5.15 & .83 \\
Self-Disclosure Total & 100.67 & 11.41 & \\
\hline
\end{tabular}


Table 2

Correlation of Personality Traits and Motivations for Self-disclosure

\begin{tabular}{|c|c|c|c|c|c|}
\hline & \multicolumn{5}{|c|}{ Motivationss for Self-Disclosure } \\
\hline & $\begin{array}{l}\text { Relieve Pent } \\
\text { up Feelings }\end{array}$ & $\begin{array}{l}\text { Understand } \\
\text { Myself } \\
\text { better }\end{array}$ & $\begin{array}{l}\text { Other } \\
\text { Needed to } \\
\text { Know }\end{array}$ & $\begin{array}{l}\text { Care What } \\
\text { Others Think }\end{array}$ & $\begin{array}{l}\text { Strengthen } \\
\text { Relationship } \\
\text { with Other }\end{array}$ \\
\hline \multicolumn{6}{|l|}{ Personality Traits } \\
\hline Conscientiousness & $-.22 *$ & $-.21 *$ & .09 & $-.26 * *$ & -.03 \\
\hline Health LOC & -.00 & .02 & -.17 & .07 & -.05 \\
\hline Interpersonal Trust & .10 & $.22 *$ & $-.23 *$ & $.22 *$ & .07 \\
\hline $\begin{array}{l}\text { Comm. } \\
\text { Competence }\end{array}$ & -.13 & -.00 & .20 & -.08 & -.07 \\
\hline Comm. Anxiety & .05 & .13 & $-.22 *$ & .11 & .04 \\
\hline
\end{tabular}

$* \mathrm{p}<.10$

$* * \mathrm{p}<.05$ 
Table 3

Correlation of Motivations and Dimensions of Self-disclosure

Dimensions of Self-Disclosure

\begin{tabular}{cccccc}
\hline \multirow{2}{*}{ Intent } & Amount & $\begin{array}{c}\text { Positive- } \\
\text { Negative }\end{array}$ & $\begin{array}{c}\text { Less } \\
\text { Control } \\
\text { of Depth }\end{array}$ & $\begin{array}{c}\text { Honesty- } \\
\text { Accuracy }\end{array}$ & $\begin{array}{l}\text { Total } \\
\text { of all 5 } \\
\text { factors }\end{array}$ \\
\hline
\end{tabular}

Motivations for

Self-disclosure

\begin{tabular}{lcccccc}
$\begin{array}{l}\text { Relieve Pent } \\
\text { up Feelings }\end{array}$ & -.16 & .07 & $-.38 * *$ & $-.22 *$ & $-.29 * *$ & $-.28 * *$ \\
$\begin{array}{l}\text { Understand } \\
\text { Myself better }\end{array}$ & -.14 & .14 & -.20 & $.52 * *$ & -.16 & .01 \\
$\begin{array}{l}\text { Other Needed } \\
\text { to Know }\end{array}$ & .00 & .04 & .03 & -.05 & -.05 & -.02 \\
$\begin{array}{l}\text { Care What } \\
\begin{array}{l}\text { Others Think } \\
\text { Strengthen }\end{array}\end{array}$ & -.07 & .17 & -.18 & $.41 * *$ & -.15 & .04 \\
$\begin{array}{l}\text { Relationship } \\
\text { with Other }\end{array}$ & $.28 * *$ & .09 & -.12 & .12 & .12 & .17 \\
\hline
\end{tabular}

$* \mathrm{p}<.10$

$* * \mathrm{p}<.05$ 
Table 4

Correlation of Personality Traits and Dimensions of Self-disclosure

Dimensions of Self-Disclosure

\begin{tabular}{cccccc}
\hline \multirow{2}{*}{ Intent } & Amount & $\begin{array}{c}\text { Less } \\
\text { Positive- } \\
\text { Negative }\end{array}$ & $\begin{array}{c}\text { Control } \\
\text { of } \\
\text { Depth }\end{array}$ & $\begin{array}{c}\text { Honesty- } \\
\text { Accuracy }\end{array}$ & $\begin{array}{c}\text { Total } \\
\text { of all 5 } \\
\text { factors }\end{array}$ \\
\hline
\end{tabular}

Personality Traits

\begin{tabular}{|c|c|c|c|c|c|c|}
\hline Conscientiousness & $.24 *$ & -.07 & $.20 *$ & -.05 & $.24 * *$ & $.21 *$ \\
\hline Health LOC & -.13 & .07 & -.15 & .10 & .09 & .01 \\
\hline Interpersonal Trust & -.13 & -.02 & .02 & .03 & .00 & -.01 \\
\hline $\begin{array}{l}\text { Comm. } \\
\text { Competence }\end{array}$ & $.41 * *$ & .01 & $.25 * *$ & .05 & .19 & $.33 * *$ \\
\hline Comm. Anxiety & $-.22 *$ & -.09 & $-.39 * *$ & .14 & $-.23 * *$ & $-.35 * *$ \\
\hline
\end{tabular}

\footnotetext{
$* p<.10$

$* * p<.05$
} 
Table 5

Correlation of Variables Under Study and Time Elapse from Diagnosis of STI to Disclosure

Time Elapse Time Elapse Controlling for target of Disclosure

Personality Traits

$\begin{array}{lcc}\text { Relieve Pent up Feelings } & .08 & -.09 \\ \begin{array}{l}\text { Understand Myself } \\ \text { better }\end{array} & .17 & .03 \\ \begin{array}{l}\text { Other Needed to Know } \\ \text { Care What Others Think }\end{array} & -.38^{* * *} & -.46^{* *} \\ \begin{array}{l}\text { Strengthen Relationship } \\ \text { with Other }\end{array} & -.01 & .30^{* *} \\ \end{array}$

Motivations for Self-Disclosure

$\begin{array}{lcc}\text { Comm. Competence } & -.38 * * & -.39 * * \\ \text { Health Locus of Control } & -.03 & -.10 \\ \text { Interpersonal Trust } & .23 * * & .17 \\ \text { Conscientiousness } & -.32 * * & -.35 * * \\ \text { Communication Anxiety } & .29 * * & .30 * *\end{array}$

Dimensions of Self-Disclosure

$\begin{array}{lcc}\text { Intent } & -.21 * & -.04 \\ \text { Amount } & .01 & -.20 \\ \text { Positive-Negative } & -.05 & -.13 \\ \text { Less Control of Depth } & .08 & .14 \\ \text { Honesty-Accuracy } & -.14 & -.10 \\ \text { Total of all 5 factors } & -.08 & -.14\end{array}$

\footnotetext{
$* \mathrm{p}<.10$

$* * \mathrm{p}<.05$
} 
Table 6

Time Elapse from Diagnosis of STI to Self-Disclosure

\begin{tabular}{lcccc} 
& Frequency & Percent & Valid Percent & $\begin{array}{c}\text { Cumulative } \\
\text { Percent }\end{array}$ \\
\hline Time Elapse & 42 & 56.8 & 57.5 & 57.5 \\
Immediately & 10 & 13.5 & 13.7 & 71.2 \\
Within One Week & 7 & 9.5 & 9.6 & 80.8 \\
Within One Month & 5 & 6.8 & 6.8 & 87.7 \\
Within One Year & 9 & 12.2 & 12.3 & 100.00 \\
Never Disclosed & 98.6 & 100.00 & \\
Total & 73 & 98.6 & \\
\hline
\end{tabular}


Appendix A

Communication Competence Scale

(CSS: Wiemann, 1977)

The following are statements about how people generally communicate with others. Answer each item as it relates to your general style of communicating in most social situations.

Complete the questionnaire by indicating the extent to which you agree or disagree with each statement by noting whether you (5) strongly agree, (4) agree, (3) neutral or undecided, (2) disagree, or (1) strongly disagree.

I find it easy to get along with others.

I adapt to changing situations.

I treat people as individuals.

I interrupt others too much.

Others find it "rewarding" to talk with me.

I deal with others effectively.

I am a good listener.

My personal relationships are cold and distant.

I am easy to talk to.

I won't argue with someone just to prove I am right.

My conversation behavior is not "smooth."

I ignore other people's feelings.

I generally know how others feel.

I let others know I understand what they mean.

I understand other people.

I am relaxed and comfortable when speaking.

I listen to what people say to me.

I like to be close and personal with people.

I generally know what type of behavior is appropriate in any given situation.

I usually do not make unusual demands on my friends.

I am an effective conversationalist.

I am supportive of others.

I do not mind meeting strangers.

I can easily put myself in another person's shoes.

I pay attention to the conversation.

I am generally relaxed when conversing with a new acquaintance.

I am interested in what others have to say.

I don't follow the conversation very well.

I enjoy social gatherings where I meet new people.

I am a likable person.

I am flexible.

I am not afraid to speak with people in authority.

People can come to me with their problems.

I generally say the right thing at the right time.

I like to use my voice and body expressively to communicate.

I am sensitive to others' needs of the moment. 
Appendix B

Interpersonal Trust Scale

(ITS: Rotter, 1967)

Please enter the corresponding number, keeping in mind your particular beliefs. Complete the questionnaire by indicating the extent to which you agree or disagree with each statement by noting whether you (5) strongly agree, (4) agree, (3) neutral or undecided, (2) disagree, or (1) strongly disagree.

Hypocrisy is on the increase in our society.

Using the honor system of not having a teacher present during exams would probably result in increased cheating.

Most people would be horrified if they knew how much news the public hears and sees is distorted.

If we really knew what was going on in international politics, the public would have reason to be more frightened than they now seem to be.

Most people can be counted on to do what they say they will do.

In dealing with strangers on is better off to be cautious until they have provided evidence that they are trustworthy.

Fear of social disgrace or punishment rather than conscience prevents most people from breaking the law.

Parents usually can be relied upon to keep their promises.

It is safe to believe that in spite of what people say most people are primarily interested in their own welfare.

Most elected public officials are really sincere in their campaign promises.

Most experts can be relied upon to tell the truth about the limits of their knowledge.

In these competitive times one has to be alert or someone is likely to take advantage of you.

Most salesmen are honest in describing their products.

Most students in school would not cheat even if they were sure of getting away with it. Most repairmen will not overcharge even if they think you are ignorant of their specialty. 
Appendix C

\author{
Revised Self-Disclosure Scale \\ (RDSD: Wheeless \& Grotz, 1976)
}

The following statements reflect how you communicate with other people in general. Complete the questionnaire by indicating the extent to which you agree or disagree with each statement by noting whether you (5) strongly agree, (4) agree, (3) neutral or undecided, (2) disagree, or (1) strongly disagree.

When I wish, my self-disclosures are always accurate reflections of who I really am. When I express my personal feelings, I am always aware of what I am doing and saying. When I reveal my feelings about myself, I consciously intend to do so. When I am self-disclosing, I am consciously aware of what I am revealing. I do not often talk about myself. My statements of my feelings are usually brief. I usually talk about myself for fairly long periods at a time. My conversation lasts the least time when I am discussing myself. I often talk about myself. I often discuss my feelings about myself. Only infrequently do I express my personal beliefs and opinions. I usually disclose positive things about myself.

On the whole, my disclosures about myself are more negative than positive. I normally reveal "bad" feelings I have about myself. I normally express my "good" feelings about myself. I often reveal more undesirable things about myself than desirable things. I usually disclose negative things about myself. On the whole, my disclosures about myself are more positive than negative. I intimately disclose who I really am, openly and fully in my conversation. Once I get started, my self-disclosures last a long time. I often disclose intimate, personal things about myself without hesitation. I feel that I sometimes do not control my self-disclosure of personal or intimate things I tell about myself. Once I get started, I intimately and fully reveal myself in my self-disclosures. I cannot reveal myself when I want to because I do not know myself thoroughly enough. I am often not confident that my expressions of my own feelings, emotions, and experiences are true reflections of myself. I always feel completely sincere when I reveal my own feelings and experiences. My self-disclosures are completely accurate reflections of who I am really am. I am not always honest in my self-disclosure.

My statements about my own feelings, emotions, and experiences are always accurate self-perceptions. I am always honest in my self-disclosures. I do not always feel completely sincere when I reveal my own feelings, emotion, behaviors or experiences 
Appendix D

Conscientiousness factor of the NEO Personality Inventory

(NEO FFI: Costa \& McCrae, 1992)

The following statements describe how people feel and react. Please respond to them on how strongly they describe you. Complete the questionnaire by indicating the extent to which you agree or disagree with each statement by noting whether you (5) strongly agree, (4) agree, (3) neutral or undecided, (2) disagree, or (1) strongly disagree.

I keep my belongings clean and neat.

I'm pretty good about pacing myself so as to get things done on time.

I am not a very methodical person.

I try to perform all the tasks assigned to me conscientiously. I have a clear set of goals and work toward them in an orderly fashion. I waste a lot of time before settling down to work.

I work hard to accomplish my goals.

When I make a commitment, I can always be counted on to follow through.

Sometimes I am not as dependable and reliable as I should be.

I am a productive person who always gets the job done.

I never seem to be able to get organized.

I strive for excellence in everything I do. 
Appendix E

$$
\begin{gathered}
\text { Health Locus of Control Scale } \\
\text { (HLOC: Wallston, Wallston, Kaplan, \& Maides, 1976) }
\end{gathered}
$$

The following statements reflect how you may feel about your health in general. Complete the questionnaire by indicating the extent to which you agree or disagree with each statement by noting whether you (5) strongly agree, (4) agree, (3) neutral or undecided, (2) disagree, or (1) strongly disagree.

If I take care of myself, I can avoid illness.

Whenever I get sick, it is because of something I've done or not done.

Good health is largely a matter of good fortune.

No matter what I do, if I am going to get sick, I will get sick.

Most people do not realize the extent to which their illnesses are controlled by accidental happenings.

I can only do what my doctor tells me to do.

There are so many strange diseases around that you can never know how or when you might pick one up.

When I feel ill, I know it is because I have not been getting the proper exercise or eating right.

People who never get sick are just plain lucky.

People's ill health results from their own carelessness.

I am directly responsible for my health. 
Appendix F

Personal Report of Communication Apprehension-24

(PRCA-24: McCroskey, 1978)

The following statements represent how you may feel when engaging in a conversation. Complete the questionnaire by indicating the extent to which you agree or disagree with each statement by noting whether you (5) strongly agree, (4) agree, (3) neutral or undecided, (2) disagree, or (1) strongly disagree.

While participating in a conversation with a new acquaintance, I feel very nervous. I have no fear of speaking up in conversations.

Ordinarily I am very tense and nervous in conversations. Ordinarily I am very calm and relaxed in conversations.

While conversing with a new acquaintance, I feel very relaxed. I'm afraid to speak up in conversations. 
Appendix $G$

\section{Demographic Information}

Please Do Not Include Your Name or Any Identifying Marks on this Packet

Your honesty and sincerity are greatly appreciated.

age:

Please use a check mark to indicate your sex:

male

female

Have you ever had a sexually transmitted infection (STI)/ sexually transmitted disease (STD)?

Please check only one:

Yes

No

Who was the first person you disclosed to about your STI/STD? The second person?

Please put a" 1 " next to first person and a " 2 " next to second person.

Family member

Friend

Romantic partner

Online (i.e., STD info. website)

Other not applicable

How long did you wait to tell someone about your STD other than a healthcare provider?

Please put a check mark next to your desired answer.

Immediately

within a week

within a month

within a year

have never told anyone

not applicable

The following statements reflect your motivation for self-disclosing. Complete the questionnaire by indicating the extent to which you agree or disagree with each statement by noting whether you (5) strongly agree, (4) agree, (3) neutral or undecided, (2) disagree, or (1) strongly disagree. 
I disclosed about my STI/STD to help relieve pent up feelings and emotions. I disclosed about my STI/STD to help understand myself better.

I disclosed about my STI/STD because I thought the other person needed to know. I disclosed about my STI/STD because I care about what others think of me. I disclosed about my STI/STD to strengthen my relationship with that person. not applicable

Thank you for your participation! 
Appendix $\mathrm{H}$

\section{Cover Letter}

March 1st, 2005

Dear Participant:

Thank you for your participation in this study. This study is being conducted in partial fulfillment for a master's thesis. The purpose of the study is to gain your insights into certain communication patterns. Your honesty in completing this questionnaire is greatly appreciated.

Please read each statement carefully and respond by supplying the answer that best represents your level of agreement with the statement. Please note that individuals under the age of 18 are not allowed to participate in this study. If you are unable to answer a question, leave it blank. There is neither a right nor wrong answer, only your answer.

Do not place write anything on the questionnaire that identifies you. All questionnaires will be kept private and anonymous. Your participation is completely voluntary. You can stop at any point without fear of penalty. There are no anticipated risks associated with this study. Your class standing, grades, job status, status on any athletic, social or academic club or team will not be affected by refusal to participate or by withdrawal from this study. Completing and returning this questionnaire indicates that you have agreed to participate in this study. This questionnaire takes about 15 minutes to complete.

Your time and effort is greatly appreciated. If you have any questions or concerns about this study, please feel free to contact me by phone at 304/293-3905 or by email cfletch3@wvu.edu. You may also contact Dr. Melanie Booth-Butterfield by phone at 304/293-3905 or by email mbooth@wvu.edu. You may also contact the Student Counseling Center/Carruth Center if you would like any additional information on the topics incorporated in this study at 304/293-4431.

Thank you for your participation,

Courtney V. Fletcher

M.A. Student 